\title{
Accelerated global cropland expansion and primary production increase in the 21 st century
}

Peter Potapov ( $\square$ potapov@umd.edu )

University of Maryland https://orcid.org/0000-0003-3977-0021

Svetlana Turubanova

University of Maryland

Matthew Hansen

University of Maryland https://orcid.org/0000-0003-0042-2767

Alexandra Tyukavina

University of Maryland

Viviana Zalles

University of Maryland

Ahmad Khan

University of Maryland

Xiao-Peng Song

Texas Tech University https://orcid.org/0000-0002-5514-0321

\section{Amy Pickens}

University of Maryland

\section{Quan Shen}

University of Maryland

Jocelyn Cortez

Centro Interdisciplinario de Investigaciones y Estudios sobre Medio Ambiente y Desarrollo

\section{Biological Sciences - Article}

Keywords: global cropland area, satellite data time-series, sustainable food production, terrestrial ecosystems

Posted Date: March 3rd, 2021

DOl: https://doi.org/10.21203/rs.3.rs-294463/v1

License: (c) (i) This work is licensed under a Creative Commons Attribution 4.0 International License. Read Full License 
Version of Record: A version of this preprint was published at Nature Food on December 23rd, 2021. See the published version at https://doi.org/10.1038/s43016-021-00429-z. 
Accelerated global cropland expansion and primary production increase in the $21^{\text {st }}$ century.

Peter Potapov $^{1}$, Svetlana Turubanova ${ }^{1}$, Matthew C. Hansen ${ }^{1}$, Alexandra Tyukavina ${ }^{1}$, Viviana Zalles ${ }^{1}$, Ahmad Khan ${ }^{1}$, Xiao-Peng Song ${ }^{2}$, Amy Pickens ${ }^{1}$, Quan Shen ${ }^{1}$, Jocelyn Cortez ${ }^{3}$

${ }^{1}$ Department of Geographical Sciences, University of Maryland, College Park, MD, USA

${ }^{2}$ Department of Geosciences, Texas Tech University, Lubbock, TX, USA

${ }^{3}$ Centro Interdisciplinario de Investigaciones y Estudios sobre Medio Ambiente y Desarrollo, Instituto Politécnico Nacional, Ciudad de México, México

Spatiotemporally consistent data on global cropland extent is a key to tracking progress toward hunger eradication and sustainable food production ${ }^{1,2}$. Here, we present an analysis of global cropland area and change for the first two decades of the $21^{\text {st }}$ century derived from satellite data time-series. We estimate 2019 cropland area to be 1,244 Mha with a

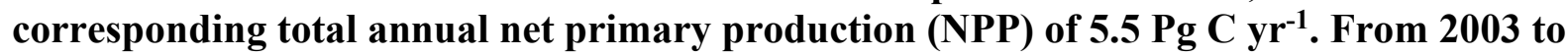
2019, cropland area increased by $9 \%$ and crop NPP by $25 \%$, primarily due to agricultural expansion in Africa and South America. Global cropland expansion accelerated over the past two decades, with a near doubling of the annual expansion rate, most notably in Africa. Half of the new cropland area (49\%) replaced natural vegetation and tree cover, indicating a conflict with the sustainability goal of protecting terrestrial ecosystems. From 2003 to 2019 global population growth outpaced cropland area expansion, and per capita cropland area decreased by $\mathbf{1 0 \%}$. However, the per capita annual crop NPP increased by $3.5 \%$ as a result of intensified agricultural land use. The presented global high-resolution cropland map time-series supports monitoring of sustainable food production at the local, national, and international levels.

Global population growth and increasing standards of living inevitably cause the expansion and intensification of global agricultural land use to fulfill growing demands for food, biofuel, and other commodities ${ }^{3-5}$. In turn, agriculture expansion and intensification threaten ecosystem functioning and lead to species extinction through habitat loss and fragmentation ${ }^{4,6,7}$. The United Nations 2030 Sustainable Development Goals (SDGs) call for balancing increasing agricultural production with maintenance of ecosystem services ${ }^{8}$. Implementation of SDGs to improve food security, protect freshwater and terrestrial ecosystems, and mitigate climate change require national policies and international cooperation that are based on consistent, independent, and timely data on agriculture extent and productivity ${ }^{2}$. Spatiotemporally consistent satellite observations provide the most accurate and cost-effective solution for global agricultural land use mapping and monitoring 9 . Satellite data have been shown to enable national and global agriculture mapping ${ }^{10-14}$. However, no globally consistent cropland time-series data at locally relevant spatial resolutions exist to date.

Here, we present a global cropland extent and change dataset that can serve as a tool for monitoring national and global progress towards SDGs. We define cropland as land used for annual and perennial herbaceous crops for human consumption, forage (including hay), and biofuel. Perennial woody crops, pastures, and shifting cultivation are excluded from the definition. The fallow length is limited to four years for the cropland class. Our definition is consistent with the arable land category reported by the Food and Agriculture Organization of 
the United Nations $(\mathrm{FAO})^{15}$. We utilized the consistently processed Landsat satellite data archive ${ }^{16}$ from 2000 to 2019 . The Landsat time-series data were transformed into multitemporal metrics that described land surface phenology. These metrics were used as independent variables for a machine learning classification to map global croplands extent. The classification models were locally calibrated using extensive training data collected by visual interpretation of freely available high spatial resolution remotely sensed data. We used a probability sample, stratified based on the cropland maps, to estimate cropland area and its associated uncertainty, and to analyze pathways of land use conversion. Sample reference data were collected through visual interpretation of Landsat and higher spatial resolution satellite images. Cropland maps were integrated with the Moderate Resolution Imaging Spectroradiometer-derived annual net primary production (NPP) ${ }^{17}$ as a proxy variable for analyzing crop productivity. The analysis was performed in four-year intervals (2000-2003, 2004-2007, 2008-2011, 2012-2015, and 20162019), with each epoch hereafter referred to by the last year of the interval.

Using probability sample data, we estimated the 2019 global cropland area to be $1244.2 \pm 62.7$ Mha (the uncertainty represents $95 \%$ confidence interval). Of the global cropland area, $55 \%$ is in Eurasia, $17 \%$ in Africa, 16\% in North and Central America, 9\% in South America, and 3\% in Australia and New Zealand (Extended Data Table 1; see Extended Data Fig. 1 for region boundaries). During the first two decades of the $21^{\text {st }}$ century, global cropland area increased by $101.9 \pm 45.1$ Mha, equivalent to $9 \%$ of the 2003 cropland area (Fig. 1). The largest cropland expansion was observed in Africa (by 53.2 \pm 39.4 Mha, or 34\%). South America had the largest relative cropland gain (by $37.1 \pm 8.7 \mathrm{Mha}$, or $49 \%$ ). Australia and New Zealand as well as Southwest Asia displayed moderate cropland expansion (below 10\% of the 2003 area). North America, Europe, North and Southeast Asia featured small net cropland area change but pronounced gross cropland gain and loss, which balanced each other at the continental scale.

From 2003 to 2019, the global population increased by $21 \%$ from 6.4 to 7.7 billion ${ }^{18}$, outpacing cropland expansion. As a result, global per capita cropland area decreased by $10 \%$, from 0.18 ha person $^{-1}$ in 2003 to 0.16 ha person $^{-1}$ in 2019. Increase in per capita cropland area was observed only in South America, while it decreased in all other continents (Fig. 2). The largest relative decrease of per capita cropland area was observed in Southwest Asia (by 19\%). Southeast Asia had the smallest 2019 per capita cropland area $\left(0.08\right.$ ha person $\left.^{-1}\right)$, while Australia and New Zealand had the largest per capita area $\left(1.34\right.$ ha person $\left.^{-1}\right)$.

Of the total 2019 cropland area, $217.5 \pm 37.7$ Mha (17\%) represent new cropland established since 2003. In South America and Africa, this proportion is the highest (39\% and 34\%, respectively). Half of the new croplands replaced natural woody and herbaceous vegetation (49\% of gross cropland gain area, Extended Data Table 2). Of that total, $11 \%$ represent dryland conversion through irrigation, mostly found in Southwest and Southeast Asia and North America. The largest proportions of natural vegetation conversion to croplands (excluding dryland irrigation) were found in Africa ( $79 \%$ of all gross cropland gain area), Southeast Asia (61\%), and South America (39\%). The other half of cropland expansion (51\%) was due to pasture conversion and recultivation of abandoned arable land. Nearly all cropland expansion in Australia, New Zealand, Europe, and Northern Asia was found within pastures and long fallows 
(with no crop cultivation for more than 4 years). In North and South America cropland expansion through the conversion of pastures and long fallows was more common $(75 \%$ and $61 \%$, respectively) than through clearing of natural vegetation.

Abandonment or conversion to other land uses affected 10\% of the 2003 cropland area (115.5 \pm 24.1 Mha). Of that area, 52\% was converted into pastures or abandoned (Extended Data Table 2); such conversions may be temporary and followed by crop recultivation years later. Industrial and residential construction and infrastructure development was the second largest driver of gross cropland loss, responsible for $16 \%$ of the total cropland area reduction. In Southeast Asia, $35 \%$ of cropland reduction was due to urban sprawl. A portion (13\%) of 2003 cropland was converted to permanent woody crops or aquaculture, with the highest proportion of such transitions in Southeast Asia (28\%). Flooding caused by surface water increase, water erosion, and reservoir construction affected cropland area on all continents ( $3 \%$ total reduction). The remaining $16 \%$ of cropland reduction represented tree plantations or restoration of natural vegetation after cropland abandonment.

A comparison of our 2003 and 2019 sample-based cropland area estimates with FAO 2003 and 2018 arable land area (Extended Data Fig. 2) shows sound agreements ( $\mathrm{R}^{2}$ of 0.94 and 0.98 for the year 2003 and 2019, respectively). Our sample-based cropland area estimate is smaller (by $16 \%$ and $11 \%$ for 2003 and 2019, respectively) compared to FAO arable land area. The FAO arable land change confirms our findings; both datasets demonstrate a net increase in global cropland area, with Africa and South America showing the largest net gains. The net loss of arable land area in North America, Europe, North and Southwest Asia reported by the FAO was not confirmed by our results.

The global Landsat-based cropland map time-series is complementary to the sample analysis in characterizing global area dynamics (Fig. 3). The sample analysis showed high accuracy of the global cropland maps with variability between regions and lower accuracies for change dynamics (Extended Data Table 3). The cropland map time-series allowed us to disaggregate change over time and conduct national-scale analyses.

Global cropland expansion accelerated over the past two decades, with a near doubling of the annual expansion rate from 5.1 to 9.0 Mha year $^{-1}$ (Extended Data Table 4). The change in annual cropland expansion rates highlights differences between cropland establishment in Africa and South America. In Africa, cropland expansion accelerated from 2004-2007 to 2016-2019 with a more than twofold increase in annual expansion rates. In contrast, cropland expansion in South America decelerated by 2019 with an annual expansion rate reduced almost by half compared to the 2004-2007 interval.

At the national level, the US had the largest cropland area by 2019 closely followed by India and China (Supplementary Information Table 4). The largest net cropland increases were found in Brazil (by 23.1 Mha, or 77\% increase over year 2003 cropland area) and India (by 15.5 Mha, or $13 \%$ ). The largest cropland area reductions were found in Russia (by 5.7 Mha, or $6 \%$ decrease over year 2003 cropland area) and Cuba (by 0.5 Mha, or 28\%). Our satellite-based 2019 cropland 
map area is comparable with the 2018 arable land extent reported by the FAO at the national scale ( $\mathrm{R}^{2}$ of 0.97 , Extended Data Fig. 3).

The global MODIS-derived annual NPP within cropland area (Extended Data Fig. 4) increased by $25 \%$ between 2003 and 2019 (from $4.4 \mathrm{Pg} \mathrm{C} \mathrm{yr}^{-1}$ to $5.5 \mathrm{Pg} \mathrm{C} \mathrm{yr}^{-1}$, Fig. 1). South America had the highest NPP increase (by $0.38 \mathrm{Pg} \mathrm{C} \mathrm{yr}^{-1}$, or $88 \%$ ) followed by Africa (by $0.29 \mathrm{Pg} \mathrm{C}^{-1}$, or $50 \%$ ) (Extended Data Table 5). The per capita annual crop NPP also increased globally by 3.5\%, balancing the per capita cropland area reduction. Two processes contributed to the global crop NPP increase, namely the increase of cropland area and the increase in crop productivity per unit area. We found that the mean NPP per unit area within stable crops increased by $10 \%$, from 402 $\mathrm{g} \mathrm{C} \mathrm{m}^{-2} \mathrm{yr}^{-1}$ in 2003 to $442 \mathrm{~g} \mathrm{C} \mathrm{m}^{-2} \mathrm{yr}^{-1}$ in 2019 . The highest NPP increase within stable crops was found in South America (from $528 \mathrm{~g} \mathrm{C} \mathrm{m}^{-2} \mathrm{yr}^{-1}$ in 2003 to $730 \mathrm{~g} \mathrm{C} \mathrm{m}^{-2} \mathrm{yr}^{-1}$ in 2019, or by $25 \%$ ). The NPP gain within stable croplands explains $34 \%$ of the total cropland NPP increase from 2003 to 2019.

The 2019 global cropland map (Fig. 3) shows that global crop distribution does not follow national boundaries, but rather reflects agricultural potential, population, and land use history. Major lowland regions of the world have been converted to homogeneous agricultural landscapes, including the Great Plains in North America, the Pampas in South America, the Pontic steppe in Europe, the North China and Manchurian Plains in East Asia, the Indo-Gangetic Plain in South Asia, parts of the Sahel region in Africa, and Southeast Australia (Extended Data Fig. 5). Cropland expansion in South America occurred synchronously in Brazil, Argentina, Paraguay, Bolivia, and Uruguay. A similar pattern of simultaneous cropland expansion was observed within Sahelian and Central African countries. In Southwest and Southeast Asia, cropland gain was mostly found in drylands, while tree plantations, orchards, aquaculture, and urban areas replaced former croplands in China and the Lower Mekong countries. In Russia, the massive cropland abandonment in the north ${ }^{19}$ was partly compensated by the recent cropland expansion in the southern steppe regions, primarily through fallow land recultivation. The crossboundary distribution of major cropland areas and synchronous cropland dynamics illustrate the importance of international cooperation to ensure global progress towards SDGs.

Global cropland maps provide spatial context on national, cross-boundary, and local crop dynamics reflecting the history of land tenure, national policies, and abrupt events like natural and man-made disasters (Extended Data Fig. 6). In Eastern Europe, the Baltic states and Russia's Kaliningrad region featured cropland expansion through recultivation of long fallows abandoned after the breakdown of the USSR, while cropland area in neighboring Poland and Belarus was relatively stable. Cereal, forage, and hay production land of the northern Great Plains have different dynamics within Canada, where we observed land abandonment or conversion to permanent pastures, and the USA, where land management has been intensified. The irrigated croplands in Saudi Arabia declined following the depletion of groundwater resources and the implementation of state policies to discourage water-intensive crop production ${ }^{20}$. The $30 \mathrm{~m}$ spatial resolution of the cropland maps supports the analysis of local dynamics factors, e.g., cropland abandonment after radioactive contamination following the 2011 nuclear disaster on the Fukushima Daiichi nuclear power plant in Japan. 
Changes in total and per capita mapped cropland area from 2003 to 2019 demonstrate the variability of national responses to the need for increased food production to feed a growing population (Extended Data Fig. 7). For most countries with moderate cropland area gains, we observed small decreases in per capita cropland area, indicating increasing stress to existing agricultural systems. In many African nations (e.g., Cameroon, Chad, Tanzania, Uganda, among others) the relatively large cropland area increases compensated for population growth and resulted in small changes in per capita cropland area. In other countries, cropland increase was not adequate to follow population growth, causing a substantial decrease of cropland per capita (e.g., in Ethiopia, Nigeria, Pakistan, Senegal, Tajikistan). Per capita cropland area decreased nearly twofold in Niger, which experienced high population growth and slow cropland expansion. Per capita cropland area reduction can be an indicator of food insecurity in poor countries that rely on subsistence agriculture, while rich countries like Saudi Arabia can compensate for cropland area decline with food imports ${ }^{21,22}$. Several African countries with rapid cropland increase (Angola, Cote d'Ivoire, Democratic Republic of the Congo, Mozambique, and Zambia) and South American countries with industrial export-oriented agricultural expansion (Brazil, Bolivia, Paraguay, and Uruguay) increased per capita cropland area. The Baltic states of Lithuania and Latvia had the largest increase of cropland per capita due to cropland gain through recultivation of agricultural lands abandoned in the 1990s coupled with a sharp population decline (more than 20\% reduction since 2000). Despite their small size, these countries are among the top-15 global wheat exporters.

More than three quarters (77\%) of the global population lives in regions with per capita cropland area and crop NPP below the year 2019 global average (Extended Data Fig. 8). The lowest per capita 2019 crop NPP was in Southwest Asia (40\% of the global average), which decreased by 7\% since 2003. Per capita cropland area in Southeast Asia in 2019 was half the global average. In contrast, per capita cropland areas and crop NPP in North America, Europe, and North Asia in 2019 were twice the global average. South America had nearly three-fold higher per capita crop NPP than the global average, and it increased by 59\% since 2003. Although per capita cropland area and crop NPP decreased by more than 10\% in Australia and New Zealand since 2003, the region still led the world in both measures in 2019. Regions with cropland area and crop NPP above the global average include the largest grain and soybean exporting countries (Australia, Argentina, Brazil, USA, Russia).

Regional accuracies (Extended Data Table 3) highlight the limitations of the Landsat-based cropland maps. North and South America, which are dominated by large-scale industrial farming have the highest accuracies. In Europe, Asia, and Africa, the global map underestimates cropland area due to spatial resolution limitations in mapping heterogeneous landscapes. Cropland maps in Australia and New Zealand overestimate cropland area due to the inclusion of intensively managed planted pastures which are not always separable from crops using Landsat data. Additionally, mapping change was shown to be more difficult with accuracies generally lower across all regions. A probability-based sample analysis is the recommended good practice approach $^{23}$ to estimating land cover and land use extent and change, including croplands. The global cropland map time-series enables a higher sampling efficiency through stratification at the sub-national, national, and global scales. The difference between our sample-based and map- 
207 based cropland area estimates and the arable land area reported by the FAO is related to the 208 definitional inconsistency. The FAO country reports may include unused arable land and other 209 agricultural land uses ${ }^{9,15}$, while our estimates represent the actively cultivated cropland area.

210 The annual MODIS NPP is the only publicly available globally consistent data that reflect recent 211 changes in crop productivity. These data have been shown to underestimate NPP compared to 212 processed-based model estimations, especially for irrigated crops ${ }^{24}$. The difference in spatial 213 resolution between Landsat-based cropland maps and MODIS-based NPP data may impede the

214 analysis of crop productivity within heterogeneous landscapes. Our Landsat-based cropland 215 extent time-series data can provide a useful input for improved NPP modeling at higher spatial 216 resolution and with better precision.

217 High-resolution satellite-based synoptic data on cropland extent and change provide the basis for 218 tracking progress toward sustainable food production at the local, national, and international 219 levels and for applying crop condition monitoring to support decision-making ${ }^{25}$. Cropland extent 220 is a key variable required to estimate emissions from agriculture and is, therefore, a part of the 221 Essential Climate Variables required for monitoring and modeling the Earth's climate ${ }^{26}$. Locally 222 relevant cropland map time-series enable the monitoring of land use conversion within high 223 conservation value ecosystems and protected areas ${ }^{27}$. The cropland extent map, integrated with

224 other high spatial and temporal resolution data, such as forest change ${ }^{28}$ and surface water extent ${ }^{29}$ 225 can provide a comprehensive overview of human-induced environmental change. The presented 226 method is suitable for monitoring of global croplands and assessing the progress of individual 227 countries towards sustainable food production. 


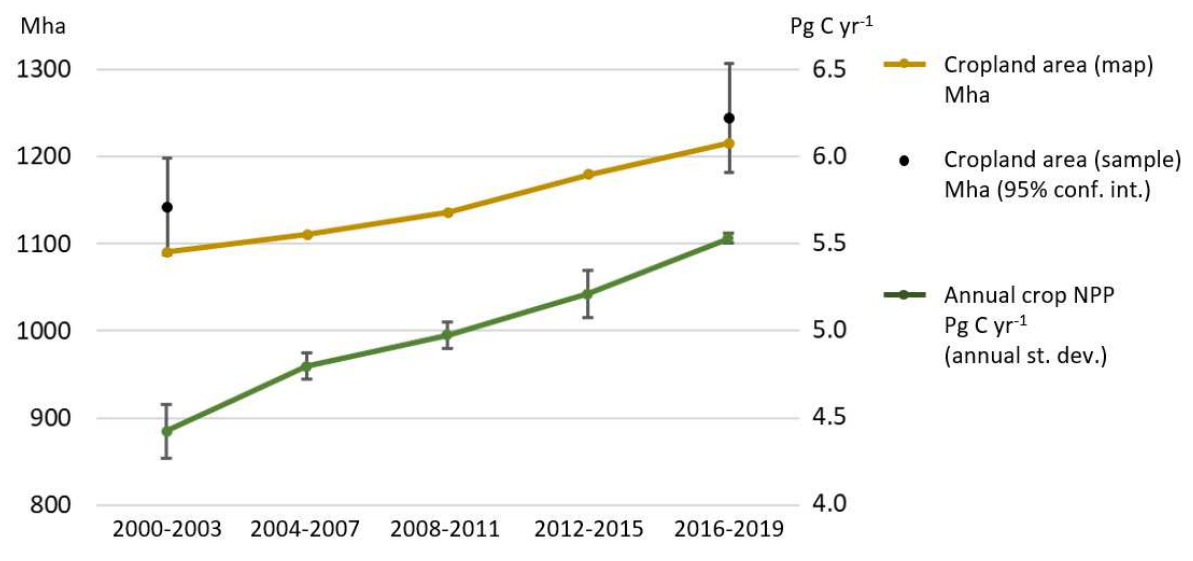

231 Fig. 1. Global cropland area (map-based and sample-based) and annual crop net primary

232 production (NPP). Cropland area was mapped for each four-year interval. Sample analysis was 233 performed only for the first and the last intervals. The MODIS-based annual NPP represents

234 four-year average within the cropland map for the corresponding time interval. The error bars for 235 sample-based crop area estimates represent 95\% confidence interval while error bars for NPP represent one standard deviation of annual values within the time interval. 


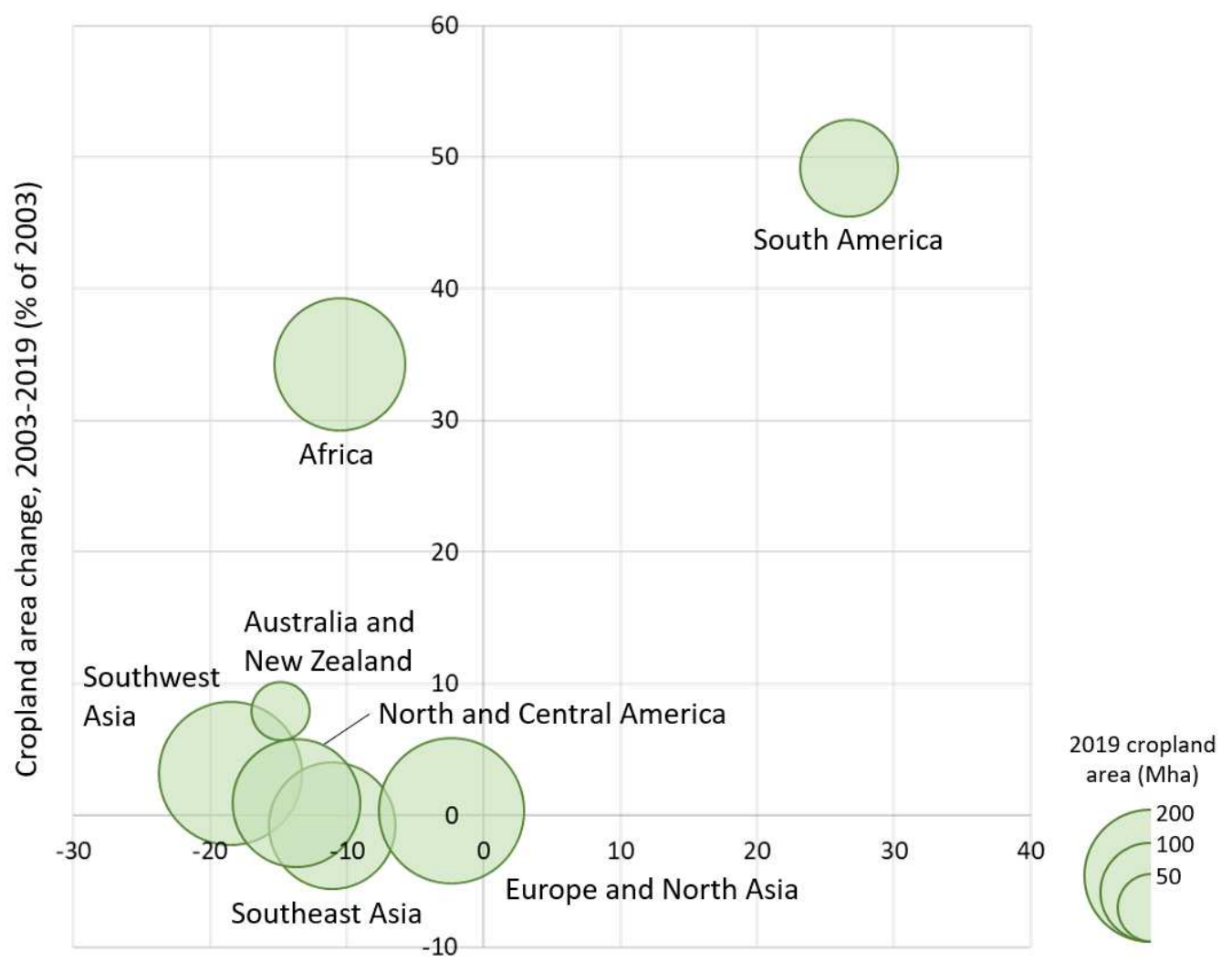

240 Fig. 2. Total and per capita cropland area change, 2003-2019, per geographic region. The size of 241 the bubbles reflects regional 2019 cropland area. 


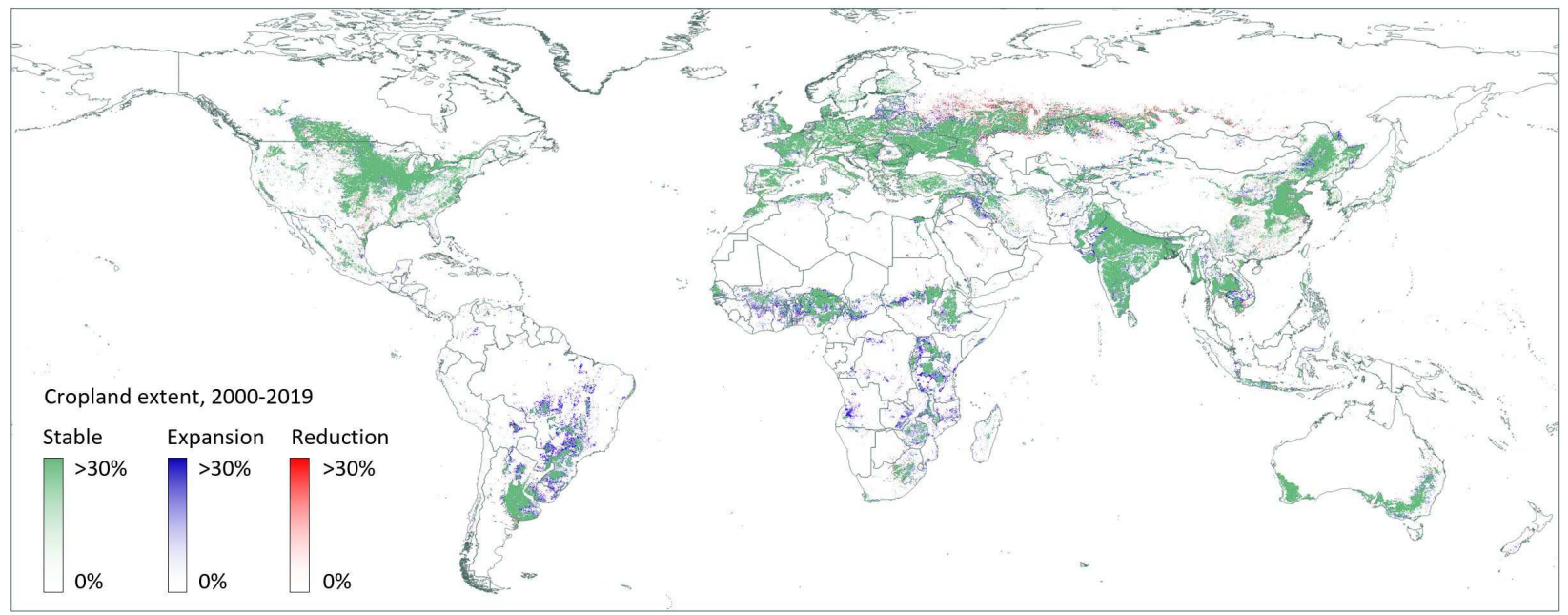

245 Fig. 3. Global cropland extent and change, 2000-2019. The map shows proportion of stable 246 cropland, cropland expansion, and cropland reduction within $0.025^{\circ} \times 0.025^{\circ}$ grid cells. The 247 original cropland map time-series has a spatial resolution of $0.00025^{\circ}$ per pixel, approximately $24830 \mathrm{~m}$ at the Equator. 


\section{Cropland Mapping Extent and Time Intervals}

253 The global boundaries for the cropland mapping were informed by the USGS global cropland map ${ }^{11}$. The cropland mapping extent was defined using the geographic $1^{\circ} \times 1^{\circ}$ degree grid. We included every $1^{\circ} \times 1^{\circ}$ grid cell that contains cropland area according to the USGS map. Small islands were excluded due to the absence of Landsat geometrically corrected data

257 (Supplementary Information Fig. 1).

258

The cropland mapping was performed at four-year intervals (2000-2003, 2004-2007, 2008-2011, 2012-2015, and 2016-2019). Using a long interval (rather than a single year) increased the number of clear-sky satellite observations in the time-series, which improves representation of land surface phenology and the accuracy of cropland detection. For each four-year interval, we mapped an area as cropland if a growing crop was detected during any of these years. This way, we implemented the criterion of the maximum fallow length: if an area was not used as cropland for more than four years, it was not included in the cropland map for the corresponding time interval.

\section{Source Landsat Data}

We employed the global 16-day normalized surface reflectance Landsat Analysis Ready Data (Landsat $\mathrm{ARD}^{16}$ ) as input data for cropland mapping. The Landsat ARD were generated from the entire Landsat archive from 1997 to 2019. The Landsat top of atmosphere reflectance was normalized using globally consistent MODIS surface reflectance as a normalization target. Individual Landsat images were aggregated into 16-day composites by prioritizing clear-sky observations.

For each four-year interval, we created a single annualized gap-free 16-day observation timeseries. For each 16-day interval, we selected the observation with the highest near-infrared reflectance value (to prioritize observations with the highest vegetation cover) from four years of Landsat data. Observations contaminated by haze, clouds, and cloud shadows, as indicated by the Landsat ARD quality layer, were removed from the analysis. If no clear-sky data were available for a 16-day interval, we filled the missing reflectance values using linear interpolation.

The 16-day time-series was transformed into a set of multitemporal reflectance metrics that provide consistent land surface phenology inputs for global cropland mapping. The multitemporal metrics methodology is provided in detail in $\operatorname{ref}^{16}$ and $\operatorname{ref}^{30}$. The Landsat metrics set was augmented with elevation data ${ }^{31}$. This way, we created spatially consistent inputs for each of the four-year intervals. The complete list of input metrics is presented in Supplementary Information Table 1.

\section{Global Cropland Mapping}

Global cropland mapping included three stages that enabled extrapolation of visually delineated cropland training data to a temporally consistent global cropland map time-series using machine 
learning. At all three stages, we employed bagged decision tree ensembles ${ }^{32}$ as a supervised classification algorithm that used class presence and absence data as the dependent variable and a set of multitemporal metrics as independent variables at a Landsat ARD pixel scale. The bagged decision tree results in a per-pixel cropland probability layer, which is thresholded at 0.5 to obtain a cropland map.

The first stage consisted of performing individual cropland classifications for a set of 924 Landsat ARD $1^{\circ} \times 1^{\circ}$ tiles for the 2016-2019 interval (Supplementary Information Fig. 1). The tiles were chosen to represent diverse global agriculture landscapes. Classification training data (cropland class presence and absence) were manually selected through visual interpretation of Landsat metric composites and high-resolution data from Google Earth. An individual supervised classification model (bagged decision trees) was calibrated and applied to each tile.

At the second stage, we used the 924 tiles that had been classified as crop/no-crop and the 20162019 metric set to train a series of regional cropland mapping models. The classification was iterated by adding training tiles and assessing the results until the resulting map was satisfactory. We then applied the regional models to each of the preceding four-year intervals, thus creating a preliminary time-series of global cropland maps.

At the third stage, we used the preliminary global cropland maps as training data to generate temporally consistent global cropland data. Because the regional models applied at the second stage were calibrated using 2016-2019 data alone, classification errors may arise due to Landsat data inconsistencies before 2016. The goal of this third stage was to create a robust spatiotemporally consistent set of locally calibrated cropland detection models. For each $1^{\circ} \times 1^{\circ}$ Landsat ARD tile $(13,451$ tiles total) we collected training data for each four-year interval from the preliminary cropland extent maps within a $3^{\circ}$ radius of the target tile, with preference to select stable crop and no-crop pixels as training. Training data from all intervals were used to calibrate a single decision tree ensemble for each ARD tile. The per-tile models were then applied to each time interval, and the results were post-processed to remove single cropland class detections and omissions within time-series and eliminate cropland patches below 0.5 ha. Manual masks to remove map artifacts (e.g., crop overestimation over temperate wetlands and flooded grasslands) were applied in some regions to improve the map quality. The final global cropland map time-series are available at https://glad.umd.edu/dataset/croplands/.

\section{Sample Analysis}

The sample analysis had two objectives: to estimate cropland area and its associated uncertainty and to assess cropland map accuracy. The analysis was performed separately for each of the seven regions outlined in Extended Data Fig. 1, as well as globally. The regional boundaries were aligned with national boundaries to enable comparison with national data. Only land pixels were considered; pixels labeled as permanent water and snow/ice in the Landsat ARD data quality layer were excluded. In each region, we selected five strata based on the map time-series corresponding to stable croplands, cropland gain and loss, possible cropland omission area, and other lands (Supplementary Information Tables 2 and 3). The possible cropland omission stratum (stratum 4) includes areas where omission errors are probable, specifically, pixels that were not 
mapped as cropland and either (a) were identified as crops by the USGS cropland map ${ }^{11}$ or (b) had the decision tree-based cropland probability between 0.1 and 0.5 . We randomly selected 100 sample units (Landsat data pixels) from each stratum (500 samples pixels per region, 3,500 in total).

Sample interpretation was performed visually using available remotely sensed data time-series, including Landsat ARD 16-day data, composites of selected multitemporal metrics, and highresolution images provided by Google Earth (Supplementary Information Fig. 2). Each sample pixel was interpreted by two experts independently and the disagreements were discussed and resolved by the research team. The interpretation legend includes the 2003-2019 cropland dynamics categories and land use transition types. The sample reference data and interpretation results are available at https://glad.umd.edu/dataset/croplands/.

\section{Area estimation}

The sample-based area estimation was performed following ${ }^{33,34}$. The 2003 and 2019 total cropland area, stable crops, gross cropland loss and gain, and net change were estimated within each region separately, and for the entire world using Eq. 1. The area and the total number of Landsat pixels for each region and each stratum are provided in Supplementary Information Table 3. For each of the 100 sample pixels sampled in each stratum, $\mathrm{p}_{u}$ was defined by class presence, e.g., for 2003 cropland, $\mathrm{p}_{u}=0$ (2003 cropland absence) or $\mathrm{p}_{u}=1$ (2003 cropland presence). The $\mathrm{p}_{u}$ was defined similarly for the 2019 cropland, stable crop, gross cropland loss and gain classes. For the net cropland area change, $\mathrm{p}_{u}$ had values 1 (cropland gain), -1 (cropland loss), and 0 (no change).

Eq. $1 \quad \hat{A}=\sum_{h=1}^{H} A_{h} \bar{p}_{h}$ where $\widehat{A}$ - estimated cropland/cropland change area;

$A_{h}$ - area of stratum $h$;

$H$ - number of sampling strata;

$\bar{p}_{h}=\frac{\sum_{u \in h} p_{u}}{n_{h}}-$ mean cropland/cropland change proportion of samples in stratum $h$; $n_{h}$ - sample size (number of sample pixels) in stratum $h$;

The standard error of area was estimated from the variances of cropland (or cropland dynamics category) class values $\mathrm{p}_{u}$ for sample pixels in each stratum using Eq. 2 . The $95 \%$ confidence interval was obtained by multiplying standard error by 1.96 .

$E q .2 S E(\hat{A})=\sqrt{\sum_{h=1}^{H} A_{h}^{2}\left(1-\frac{n_{h}}{N_{h}}\right) \frac{s_{p h}^{2}}{n_{h}}}$

where $S E(\hat{A})$ - standard error of cropland/cropland change class area; $s_{p h}^{2}=\frac{\sum_{u \in h}\left(p_{u}-\overline{p_{h}}\right)^{2}}{n_{h h}-1}$, sample variance for stratum $h$. 


\section{Proportion of land use trajectories}

355 We analyzed the land-use trajectories of cropland loss and gain using reference sample data within cropland gain and loss strata only. Inclusion of sample pixels from other strata where cropland change was detected would have inflated the area of land use trajectories that these pixels represent (i.e., if a sample pixel from a stable cropland stratum was interpreted as cropland gain due to forest clearing, including the proportion of forest clearing from this large stratum will dominate the total regional estimate). The proportion of each land use trajectory (within cropland gain and loss separately) was estimated from the sample and reported as the percent of the total gain or loss along with its standard error (Extended Data Table 2). Combined ratio estimator for stratified random sampling ${ }^{34}$ was employed to estimate the percentages (Eq. 3).

Eq. $3 \hat{R}=\frac{\sum_{h=1}^{H} A_{h} \bar{y}_{h}}{\sum_{h=1}^{H} A_{h} \bar{x}_{h}} \times 100$

where $\widehat{R}$ - estimated class proportion expressed as percentage;

$H$ - number of sampling strata;

$A_{h}$ - area of stratum $h$;

$\bar{y}_{h}=\frac{\sum_{u \in h} y_{u}}{n_{h}}$, the sample mean of the $y_{u}$ values in stratum $h$ where $y_{u}=1$ if pixel $u$ is classified as belonging to a specific transition in the reference sample interpretation, and $y_{u}=0$ otherwise;

$\bar{x}_{h}=\frac{\sum_{u \in h} x_{u}}{n_{h}}$, the sample mean of the $x_{u}$ values in stratum $h$, where $x_{u}=1$ if pixel $u$ is classified as any cropland loss/gain in the reference sample interpretation, and $x_{u}$ $=0$ otherwise.

The standard error of the estimated ratio of class proportion expressed as percentage was calculated using Eq. 4.

$E q .4 S E(\widehat{R})=\sqrt{\frac{1}{\hat{X}^{2}} \sum_{h=1}^{H} A_{h}^{2}\left(1-\frac{n_{h}}{N_{h}}\right)\left(s_{y h}^{2}+\widehat{R}^{2} s_{x h}^{2}-2 \widehat{R} s_{x y h}\right) / n_{h} \times 100}$

where $S E(\widehat{R})$ - standard error of the estimated proportion expressed as percentage; $N_{h}$ - total number of pixels in stratum $h$;

$n_{h}$ - number of sample pixels in stratum $h$;

$\widehat{X}=\sum_{h=1}^{H} A_{h} \bar{x}_{h}$ - the estimated total area of cropland loss/gain expressed in area units;

$s_{y h}^{2}$ and $s_{x h}^{2}$ are the sample variances in stratum $h$ and $s_{x y h}$ is the sample covariance in stratum $h$ estimated as follows:

$s_{y h}^{2}=\sum_{u \in h}\left(y_{u}-\bar{y}_{h}\right)^{2} /\left(n_{h}-1\right)$

$s_{x h}^{2}=\sum_{u \in h}\left(x_{u}-\bar{x}_{h}\right)^{2} /\left(n_{h}-1\right)$

$s_{x y h}=\sum_{u \in h}\left(y_{u}-\bar{y}_{h}\right)\left(x_{u}-\bar{x}_{h}\right) /\left(n_{h}-1\right)$ 


\section{Map accuracy}

368 The map accuracy metrics include overall accuracy (the proportion of correctly mapped sample pixels), user's accuracy of the cropland class (which reflects the cropland class commission) and producer's accuracy of the cropland class (which reflects the cropland class omission) ${ }^{33}$. All

371 accuracy metrics and respective standard errors are presented as percentages (Extended Data 372 Table 3).

373 To estimate overall accuracy, we defined $y_{u}=1$ if pixel $\mathrm{u}$ is classified correctly and $y_{u}=0$ if 374 pixel $u$ is classified incorrectly. The estimator for overall accuracy is then expressed by Eq. 5, 375 and standard error for overall accuracy is computed using Eq. 6.

Eq. $5 \quad \hat{O}=\frac{\sum_{h=1}^{H} N_{h} \overline{y_{h}}}{N} \times 100$ where $\hat{O}$ - estimated overall accuracy, expressed as percentage;

$H$ - number of sampling strata;

$N_{h}-$ total number of pixels in stratum $h$;

$N$ - total number of pixels in the reporting region;

$\bar{y}_{h}=\sum_{u \in h} y_{u} / n_{h}$ is the sample mean of the $y_{u}$ values in stratum $h$.

Eq. 6

$$
S E(\hat{O})=\sqrt{\frac{1}{N^{2}} \sum_{h=1}^{H} N_{h}^{2}\left(1-n_{h} / N_{h}\right) s_{y h}^{2} / n_{h}} \times 100
$$

where $S E(\widehat{O})$ - standard error of the overall accuracy, expressed as percentage; $n_{h}$ - number of sample pixels in stratum $h$;

$s_{y h}^{2}$ - the sample variance: $s_{y h}^{2}=\sum_{u \in h}\left(y_{u}-\bar{y}_{h}\right)^{2} /\left(n_{h}-1\right)$

For estimating user's accuracy of the croplands class, we define $y_{u}=1$ if sample pixel $u$ is correctly mapped as cropland otherwise $y_{u}=0$, and define $x_{u}=1$ if sample pixel $u$ is mapped cropland, otherwise $x_{u}=0$. For the producer's accuracy, define $y_{u}=1$ if sample pixel $u$ is correctly mapped as cropland, otherwise $y_{u}=0$, and define $x_{u}=1$ if sample pixel $u$ was interpreted as cropland, otherwise $x_{u}=0$. The estimator of user's accuracy and producer's accuracy is then expressed as a ratio estimator (Eq. 7) and their standard error calculated using Eq. 8, which are similar to Eq. 3 and 4, except that the strata are weighted by their total number of pixels $\left(N_{h}\right)$ instead of the areas $\left(A_{h}\right)$ for the purposes of map accuracy assessment (with pixel

Eq. 7

$$
\widehat{R}=\frac{\sum_{h=1}^{H} N_{h} \bar{y}_{h}}{\sum_{h=1}^{H} N_{h} \bar{x}_{h}} \times 100
$$

where $\widehat{R}$ - estimated user's/producer's accuracy, expressed as percentage. 
Eq. 8

$$
S E(\hat{R})=\sqrt{\frac{1}{\hat{X}^{2}} \sum_{h=1}^{H} N_{h}^{2}\left(1-\frac{n_{h}}{N_{h}}\right)\left(s_{y h}^{2}+\hat{R}^{2} s_{x h}^{2}-2 \hat{R} s_{x y h}\right) / n_{h}} \times 100
$$

where $S E(\hat{R})$ - standard error of the estimated user's/producer's accuracy, expressed as percentage.

$$
\widehat{X}=\sum_{h=1}^{H} N_{h} \bar{x}_{h}
$$

388

\section{Crop Net Primary Production}

The crop net primary production (NPP) was evaluated using the globally consistent Collection 6 MODIS-based annual year-end gap-filled NPP product (MOD17A3HGF ${ }^{17}$ ). The product provides the sum of total daily NPP through the year at a $500 \mathrm{~m}$ spatial resolution $\left(\mathrm{Kg} \mathrm{C} \mathrm{m}^{-2}\right.$ year $^{-1}$ ). The annual NPP data were resampled to our Landsat ARD data grid and were overlaid with the corresponding four-year cropland maps to calculate total and per unit area NPP for each region and each year. We used average annual NPP for each four-year interval, except for the 2000-2003 interval, where a three-year average was used instead to avoid using the year 2000 when MODIS data were incomplete. The standard deviation of the annual estimates is provided along with the interval average as an uncertainty metric.

\section{Per capita cropland area and crop NPP}

We employed the 2019 Revision of World Population Prospects ${ }^{18}$ to calculate global, regional, and national population for years 2003 and 2019. Because the boundaries of analysis regions (Extended Data Fig. 1) are aligned with country boundaries, we were able to summarize the regional population totals from national data. The population data were related to our samplebased (for global and regional estimates) and map-based (for national estimates) cropland area to estimate per capita cropland area and change. Similarly, we related regional crop NPP to population data to estimate per capita crop NPP for 2003 and 2019.

\section{References}

1. The World Bank. Global Strategy to Improve Agricultural and Rural Statistics. (2011).

2. Statistical Commission pertaining to the 2030 Agenda for Sustainable Development. Global indicator framework for the Sustainable Development Goals and targets of the 2030 Agenda for Sustainable Development. (2020).

3. Godfray, H. C. J. et al. Food security: The challenge of feeding 9 billion people. Science 327, 812-818 (2010).

4. Tilman, D., Balzer, C., Hill, J. \& Befort, B. L. Global food demand and the sustainable intensification of agriculture. Proc. Natl. Acad. Sci. U.S.A. 108, 20260-20264 (2011).

5. Foley, J. A. et al. Global consequences of land use. Science 309, 570-574 (2005).

6. Crist, E., Mora, C. \& Engelman, R. The interaction of human population, food production, and biodiversity protection. Science 356, 260-264 (2017). 
7. Gibbs, H. K. et al. Tropical forests were the primary sources of new agricultural land in the 1980s and 1990s. Proc. Natl. Acad. Sci. U.S.A. 107, 16732-16737 (2010).

8. UN General Assembly. Transforming our world: the 2030 Agenda for Sustainable Development. (2015).

9. See, L. et al. Improved global cropland data as an essential ingredient for food security. Global Food Security 4 37-45 (2015).

10. Ramankutty, N., Evan, A. T., Monfreda, C. \& Foley, J. A. Farming the planet: 1. Geographic distribution of global agricultural lands in the year 2000. Global Biogeochem. Cycles 22, 1003 (2008).

11. Teluguntla, P. et al. Global Cropland Area Database ( GCAD ) derived from Remote Sensing in Support of Food Security in the Twenty-first Century : Current Achievements and Future Possibilities. Remote Sens. Handb. II, 1-45 (2015).

12. Boryan, C., Yang, Z., Mueller, R. \& Craig, M. Monitoring US agriculture: The US department of agriculture, national agricultural statistics service, cropland data layer program. Geocarto Int. 26, $341-358$ (2011).

13. Pittman, K., Hansen, M. C., Becker-Reshef, I., Potapov, P. V. \& Justice, C. O. Estimating Global Cropland Extent with Multi-year MODIS Data. Remote Sens. 2, 1844-1863 (2010).

14. Hu, Q. et al. Global cropland intensification surpassed expansion between 2000 and 2010: A spatio-temporal analysis based on GlobeLand30. Sci. Total Environ. 746, (2020).

15. FAO. A system of integrated agricultural censuses and surveys. Volume 1. World Programme for the Census of Agriculture 2010 http://www.fao.org/3/a-a0135e.pdf (UN Food and Agriculture Organization, Rome, 2005).

16. Potapov, P. et al. Landsat Analysis Ready Data for Global Land Cover and Land Cover Change Mapping. Remote Sens. 12, 426 (2020).

17. Zhao, M., Heinsch, F. A., Nemani, R. R. \& Running, S. W. Improvements of the MODIS terrestrial gross and net primary production global data set. Remote Sens. Environ. 95, 164-176 (2005).

18. United Nations, Department of Economic and Social Affairs, Population Division. World Population Prospects 2019: Volume I: Comprehensive Tables. (2019).

19. Prishchepov, A. V., Radeloff, V. C., Baumann, M., Kuemmerle, T. \& Müller, D. Effects of institutional changes on land use: Agricultural land abandonment during the transition from statecommand to market-driven economies in post-Soviet Eastern Europe. Environ. Res. Lett. 7, 024021 (2012).

20. Ouda, O. K. M. Impacts of agricultural policy on irrigation water demand: a case study of Saudi Arabia. Int. J. Water Resour. Dev. 30, 282-292 (2014).

21. Porkka, M., Guillaume, J. H. A., Siebert, S., Schaphoff, S. \& Kummu, M. The use of food imports to overcome local limits to growth. Earth's Futur. 5, 393-407 (2017).

22. Suweis, S., Rinaldo, A., Maritan, A. \& D'Odorico, P. Water-controlled wealth of nations. Proc. Natl. Acad. Sci. U.S.A. 110, 4230-4233 (2013).

23. IPCC. Good Practice Guidance for Land Use, Land-Use Change and Forestry. (Institute for Global Environmental Strategies for the IPCC, 2003). 
24. Jaafar, H. H. \& Ahmad, F. A. Crop yield prediction from remotely sensed vegetation indices and primary productivity in arid and semi-arid lands. Int. J. Remote Sens. 36, 4570-4589 (2015).

25. Becker-Reshef, I. et al. Strengthening agricultural decisions in countries at risk of food insecurity: The GEOGLAM Crop Monitor for Early Warning. Remote Sens. Environ. 237, 111553 (2020).

26. Wolf, J. et al. Biogenic carbon fluxes from global agricultural production and consumption. Global Biogeochem. Cycles 29, 1617-1639 (2015).

27. Vijay, V. \& Armsworth, P. R. Pervasive cropland in protected areas highlight trade-offs between conservation and food security. Proc. Natl. Acad. Sci. U.S.A. 118, e2010121118 (2021).

28. Hansen, M. C. et al. High-resolution global maps of 21st-century forest cover change. Science 342, 850-853 (2013).

29. Pickens, A. H. et al. Mapping and sampling to characterize global inland water dynamics from 1999 to 2018 with full Landsat time-series. Remote Sens. Environ. 243, 111792 (2020).

30. Potapov, P. et al. Mapping global forest canopy height through integration of GEDI and Landsat data. Remote Sens. Environ. 253, 112165 (2021).

31. Jarvis A., Reuter H. I., Nelson A. \& Guevara E. Hole-filled seamless SRTM data V4. http://srtm.csi.cgiar.org (International Centre for Tropical Agriculture, 2008).

32. Breiman, L. Bagging predictors. Mach. Learn. 24, 123-140 (1996).

33. Stehman, S. V. Estimating area and map accuracy for stratified random sampling when the strata are different from the map classes. Int. J. Remote Sens. 35, 4923-4939 (2014).

34. Cochran W. G. Sampling Techniques. (John Wiley \& Sons, 1977).

\section{Data and Code Availability}

All global cropland maps, cropland dynamic maps, and sample data available at https://glad.umd.edu/dataset/croplands/. The global Landsat ARD data, metric generation and image classification codes are available from https://glad.umd.edu/ard.

\section{Author Contributions}

P.P. designed the research and performed the global mapping; P.P., S.T., and A.T conducted the sample analysis; P.P., A.T., X.S., V.Z., A.P., and M.H. wrote the manuscript; V.Z., A.K., Q.S, and J.C. provided calibration data; A.P. designed data visualization. 
Extended Data

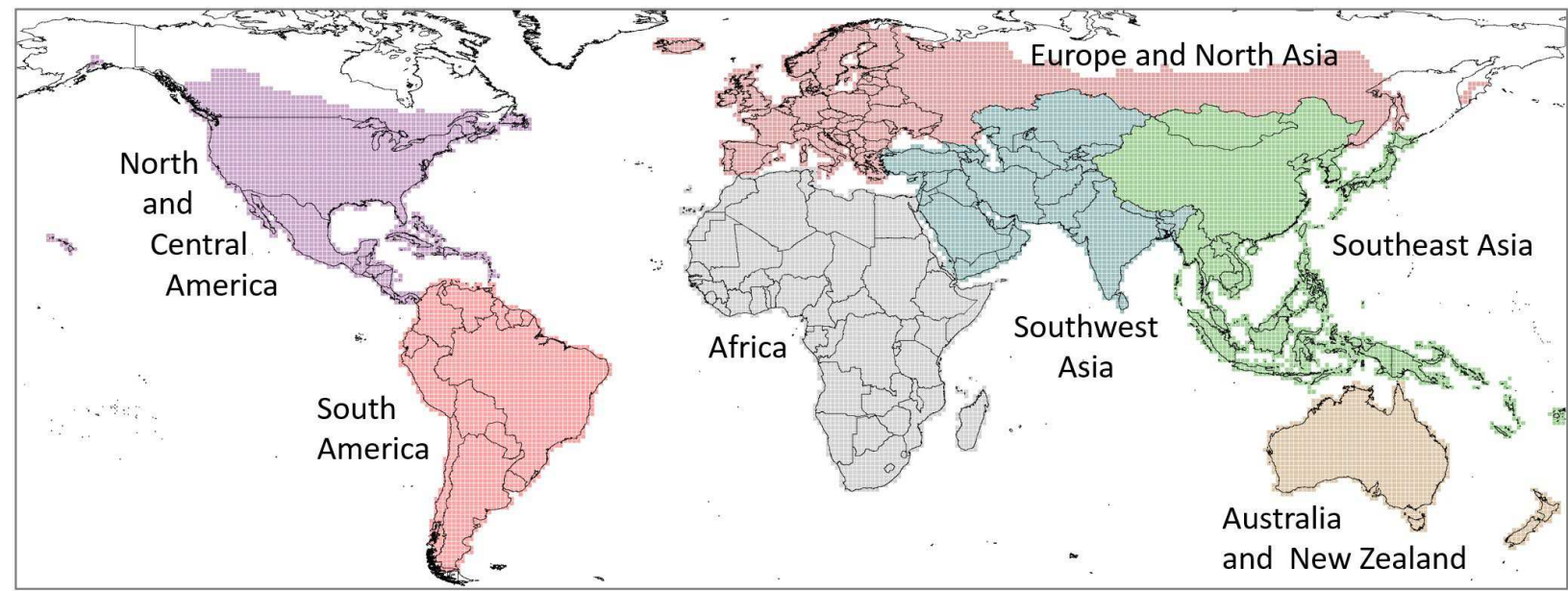

492 Extended Data Fig. 1. Regions of analysis.
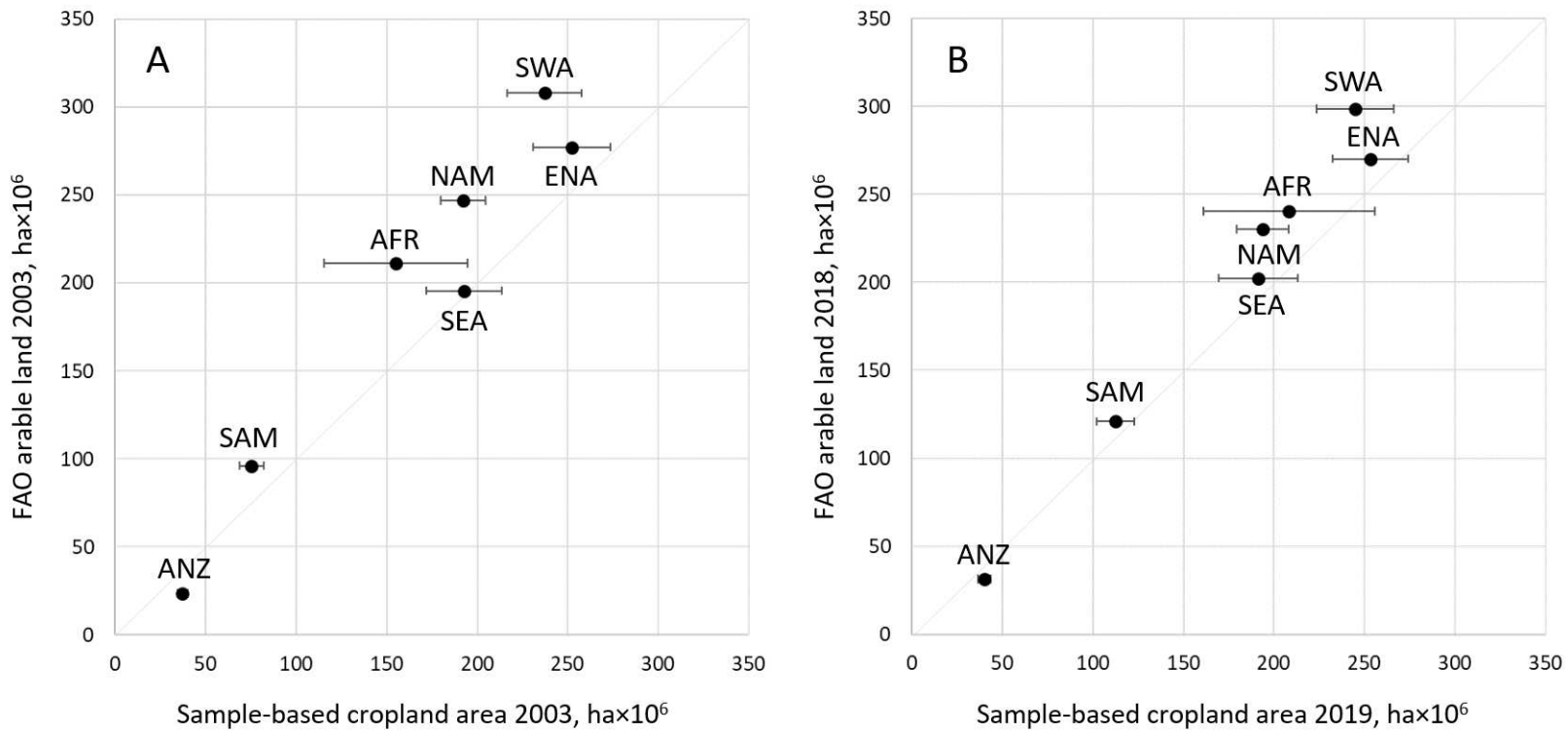

Extended Data Fig. 2. Comparison of FAO arable land area estimates with sample-based cropland area by region. Error bars represent the 95\% confidence interval of the sample-based area estimates. Region abbreviations: AFR - Africa; SWA - Southwest Asia; ANZ - Australia and New Zealand; SEA - Southeast Asia; ENA - Europe and North Asia; NAM - North and 498 Central America; SAM - South America. 


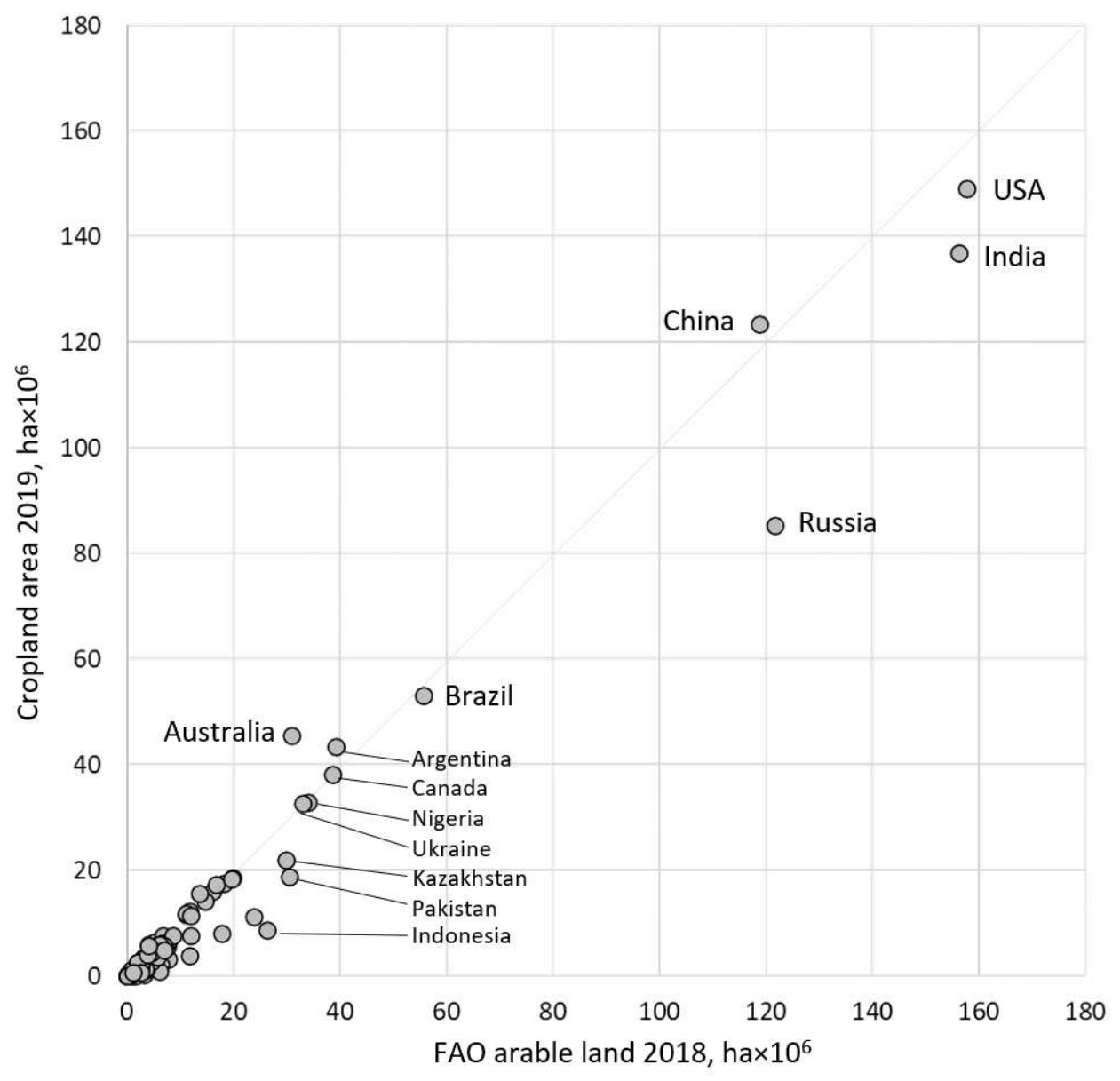

500 Extended Data Fig. 3. Per-country comparison between 2018 FAO arable land area and 2019 501 map-based cropland area from this study.

502 


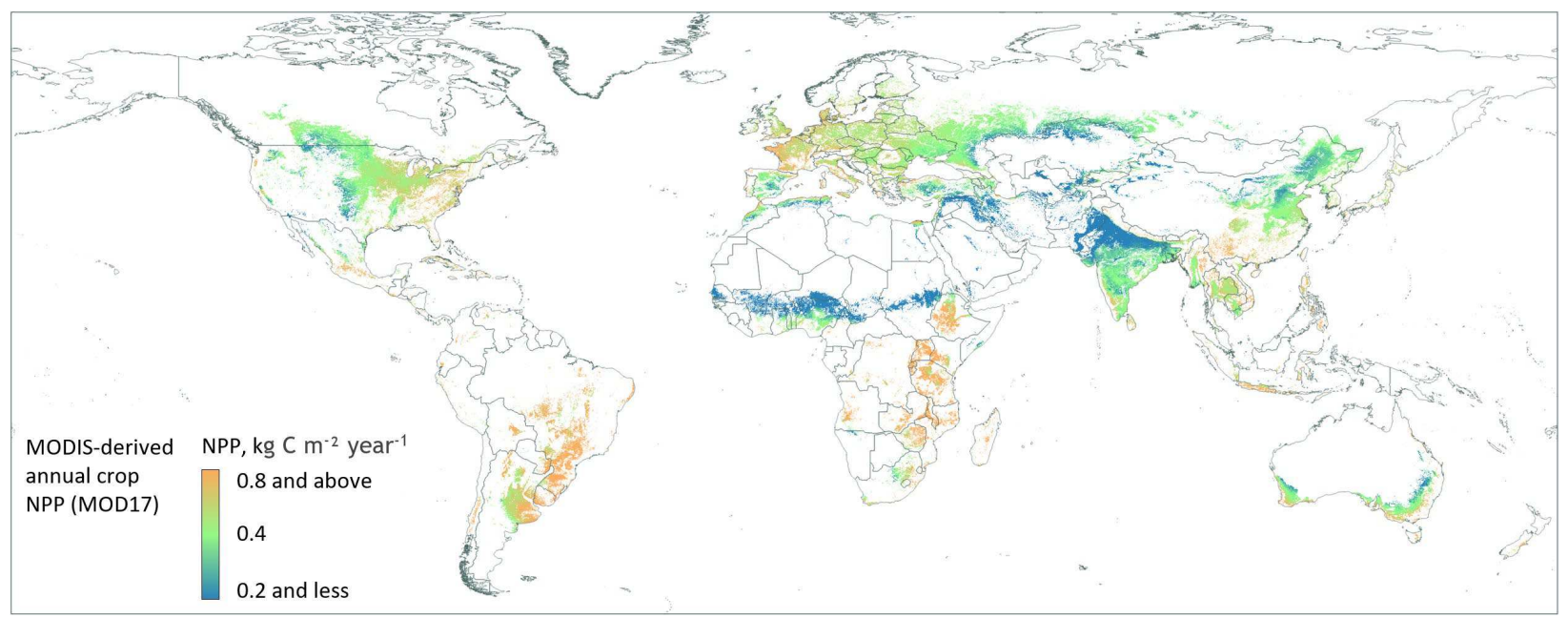

505 Extended Data Fig. 4. MODIS-derived annual NPP (from MOD17 product) within the mask of 506 cropland for the 2016-2019 interval. The NPP data represent the four-year average for the 20165072019 interval.

508 


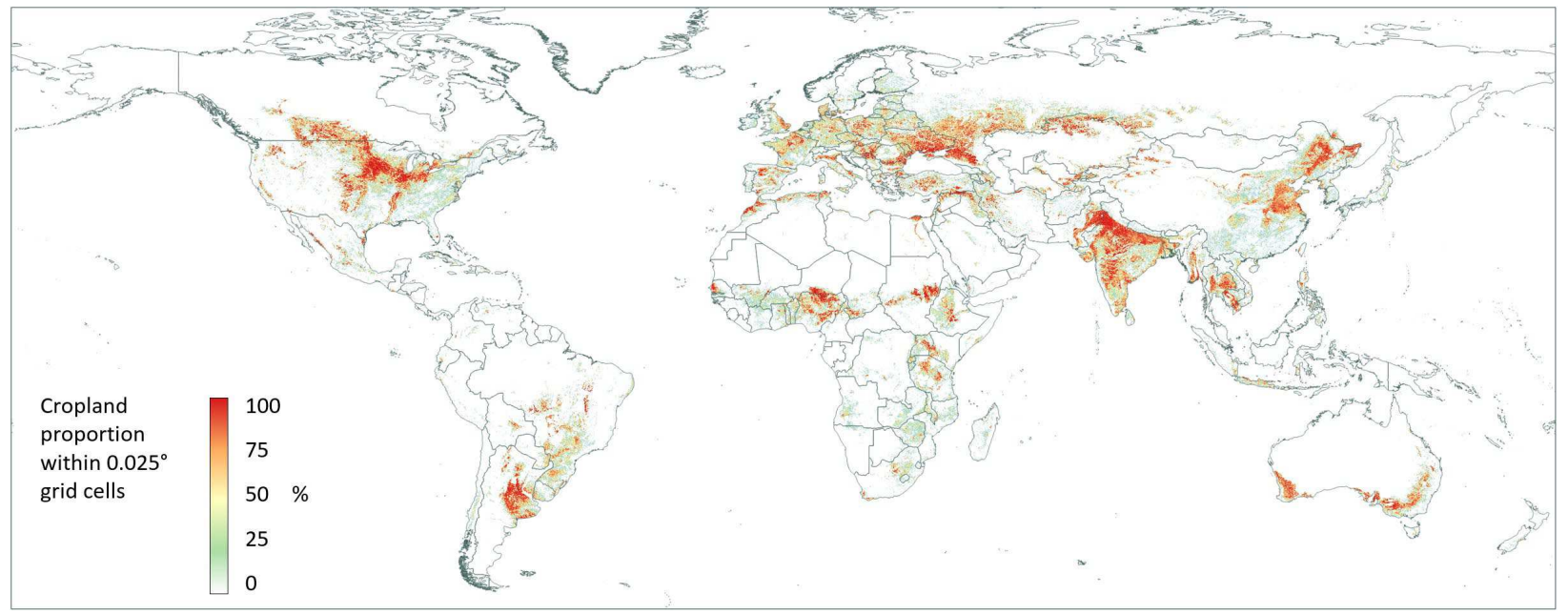

511 Extended Data Fig. 5. 2019 cropland proportion within $0.025^{\circ} \times 0.025^{\circ}$ grid cells. The original

512 cropland map has a spatial resolution of $0.00025^{\circ} \times 0.00025^{\circ}$ per pixel, approximately $30 \mathrm{~m}$ at the 513 Equator. 

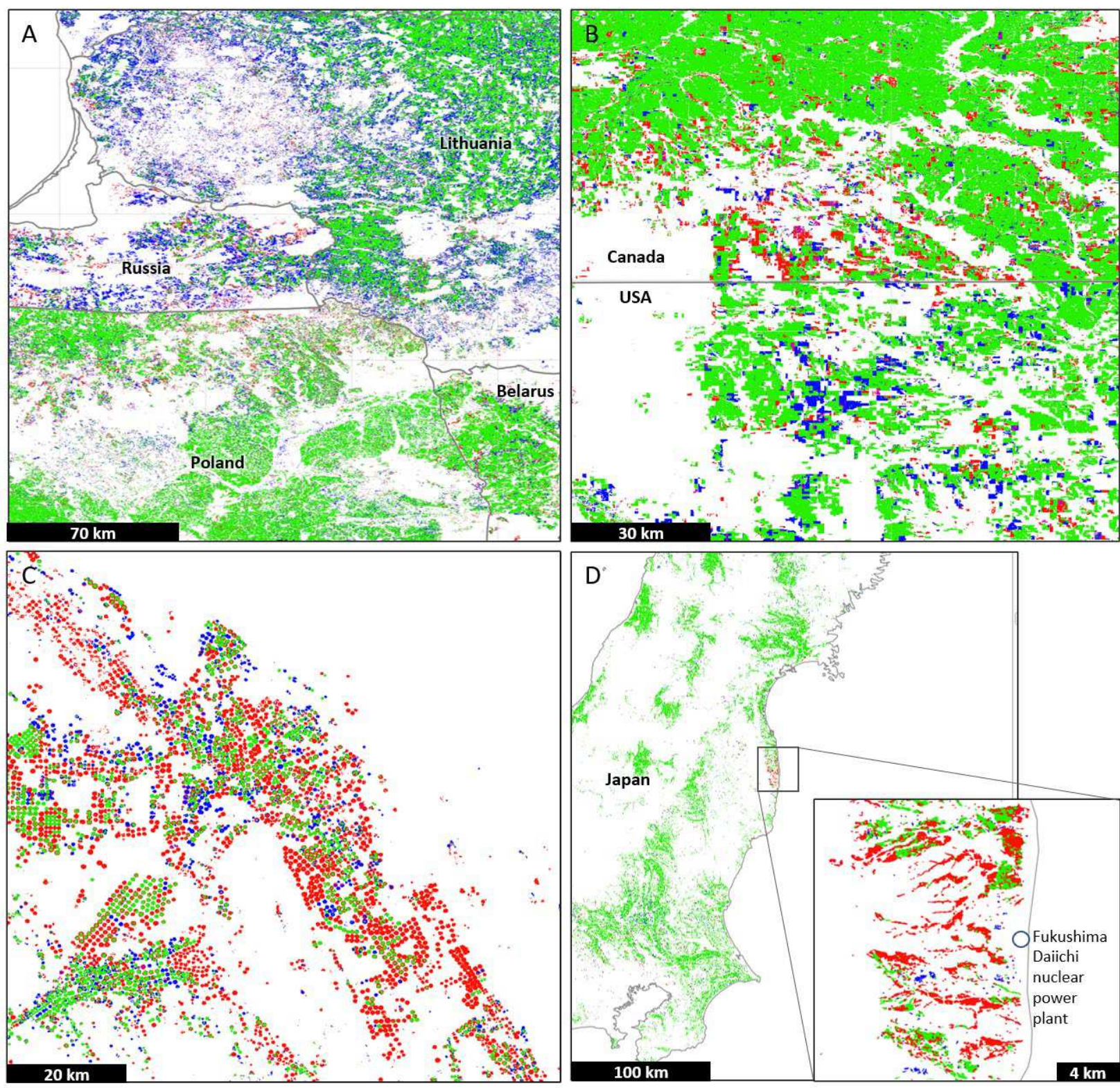

- Cropland gain $\square$ Irregular cropland dynamics

515 Extended Data Fig. 6. Regional-to-local scale examples of cropland dynamics, 2000-2019. A 516 Cross-boundary cropland dynamics in Eastern Europe (center at $22.48^{\circ}, 54.35^{\circ}$ ); B - Cropland 517 dynamics on the border between Saskatchewan, Canada, and Montana, the USA (center at $518-106.08^{\circ}, 48.99^{\circ}$ ); C - Decline of irrigated cropland area, Saudi Arabia (center at $43.58^{\circ}$, $51927.14^{\circ}$ ); D - Cropland abandonment after 2011 nuclear disaster on Fukushima Daiichi nuclear 520 power plant, Japan (zoom-in image center at $141.03^{\circ}, 37.42^{\circ}$ ) 


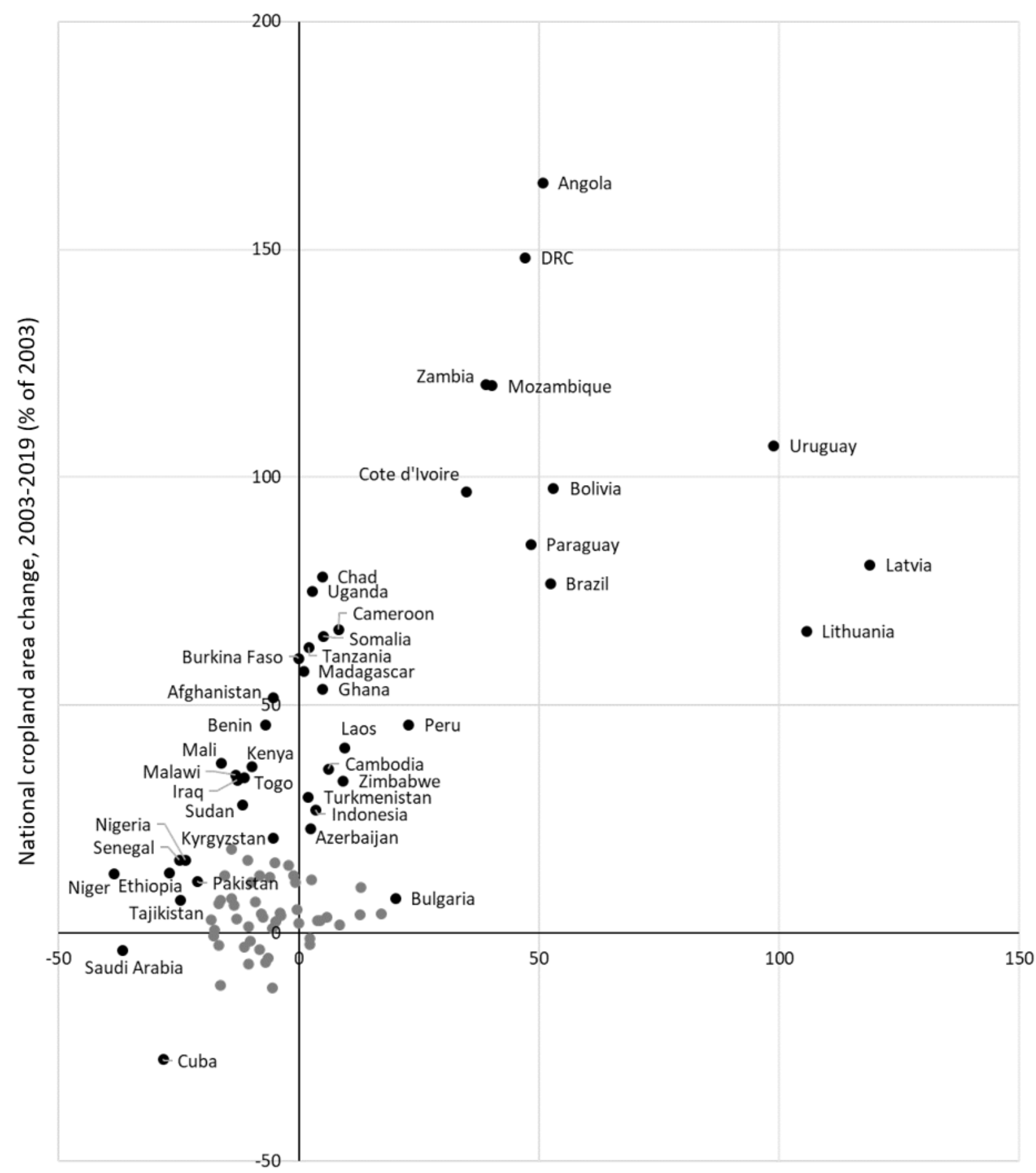

Per capita national cropland area change, 2003-2019 (\% of 2003)

522 Extended Data Fig. 7. National total and per-capita cropland area change from 2003 to 2019.

523 Countries with change below 20\% are shown in gray and not labeled. Only countries with 2019

524 cropland area above 1 Mha were analyzed. DRC stands for the Democratic Republic of the

525 Congo. 


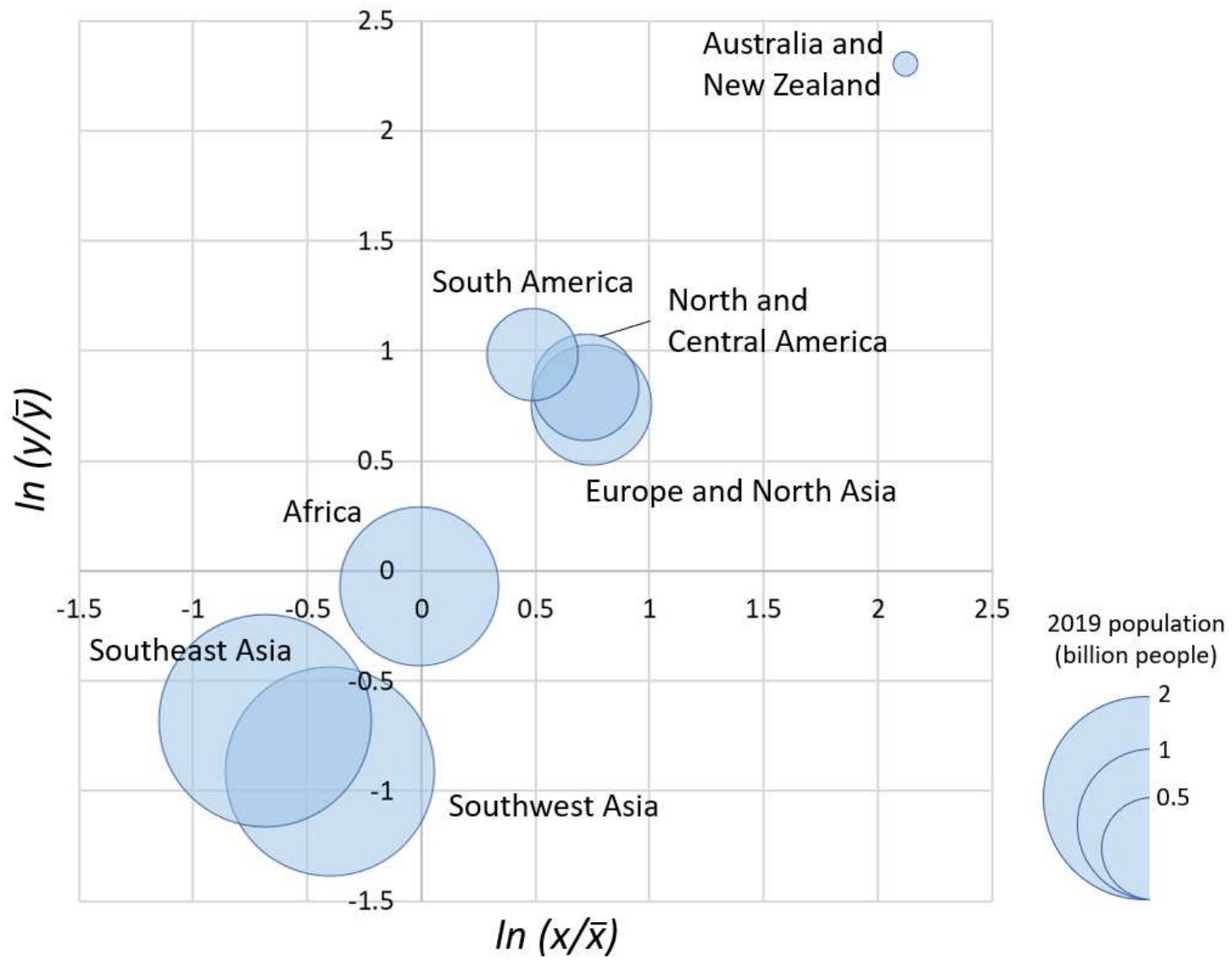

528 Extended Data Fig. 8. Regional comparison of the values of natural logarithm of the ratio of

529 regional $(x)$ and global $(\bar{x}) 2019$ per capita sample-based cropland area, ha person ${ }^{-1}$ (x axis); and 530 values of natural logarithm of the ratio of regional $(y)$ and global $(\bar{y}) 2019$ per capita crop NPP, $531 \mathrm{~kg} \mathrm{C}$ year $^{-1}$ person $^{-1}$ (y axis). The size of the bubbles reflects 2019 regional population. 
534 Extended Data Table 1. The regional and global map-based and sample-based cropland and 535 cropland dynamics areas (Mha). Sample-based estimates include 95\% confidence intervals in 536 parenthesis.

\begin{tabular}{|c|c|c|c|c|c|c|}
\hline & & $\begin{array}{l}\text { Cropland area } \\
2000-2003\end{array}$ & $\begin{array}{l}\text { Cropland area } \\
2016-2019\end{array}$ & $\begin{array}{l}\text { Net change } \\
2003-2019\end{array}$ & $\begin{array}{l}\text { Gross gain } \\
2003-2019\end{array}$ & $\begin{array}{l}\text { Gross loss } \\
2003-2019\end{array}$ \\
\hline \multirow{2}{*}{ Africa } & map & 142.6 & 189.6 & 47.0 & 62.1 & 15.1 \\
\hline & sample & $155.1(39.8)$ & 208.3 (47.4) & $53.2(39.4)$ & 71.5 (33.9) & $18.3(19.4)$ \\
\hline \multirow{2}{*}{ Southwest Asia } & map & 224.9 & 250.9 & 26.0 & 42.6 & 16.6 \\
\hline & sample & $237.3(20.6)$ & $244.8(21.4)$ & 7.5 (11.7) & $29.3(7.1)$ & $21.8(9.1)$ \\
\hline \multirow{2}{*}{$\begin{array}{l}\text { Australia and } \\
\text { New Zealand }\end{array}$} & map & 42.8 & 46.0 & 3.2 & 5.2 & 2.0 \\
\hline & sample & $37.3(2.7)$ & $40.3(3.5)$ & $3.0(2.2)$ & $4.0(2.1)$ & $1.1(0.2)$ \\
\hline \multirow{2}{*}{ Southeast Asia } & map & 172.9 & 184.5 & 11.6 & 30.9 & 19.3 \\
\hline & sample & $192.7(20.9)$ & $191.1(21.8)$ & $-1.6(8.6)$ & $23(4.1)$ & $24.6(7.4)$ \\
\hline \multirow{2}{*}{$\begin{array}{l}\text { Europe and } \\
\text { North Asia }\end{array}$} & map & 234.7 & 233.7 & -1.1 & 29.5 & 30.5 \\
\hline & sample & $252.3(21.3)$ & $253.2(20.7)$ & $0.9(6.8)$ & $25.3(6.2)$ & $24.4(2.5)$ \\
\hline \multirow{2}{*}{$\begin{array}{l}\text { North and } \\
\text { Central America }\end{array}$} & map & 196.9 & 201.5 & 4.6 & 21.3 & 16.7 \\
\hline & sample & $192.1(12.4)$ & 193.9 (14.4) & 1.8 (11.9) & $20.8(9.2)$ & $19(7.4)$ \\
\hline \multirow{2}{*}{ South America } & map & 75.4 & 109.3 & 33.8 & 41.3 & 7.5 \\
\hline & sample & $75.5(6.6)$ & $112.6(10.3)$ & $37.1(8.7)$ & $43.5(8.6)$ & $6.4(1.5)$ \\
\hline \multirow{2}{*}{ World } & map & 1090.3 & 1215.5 & 125.2 & 232.9 & 107.7 \\
\hline & sample & $1142.3(55.8)$ & $1244.2(62.7)$ & $101.9(45.1)$ & 217.5 (37.7) & 115.5 (24.1) \\
\hline
\end{tabular}

537

538 
540 Extended Data Table 2. Relative importance of different types of land use conversions for 541 cropland establishment (gain) and abandonment (loss), estimated from sample reference data. 542 The analysis was restricted to mapped cropland loss and gain areas. The values in the table 543 represent percent of each conversion type from the total cropland loss or gain area in each region 544 and globally (with standard error in parenthesis). Region abbreviations: AFR - Africa; SWA 545 Southwest Asia; ANZ - Australia and New Zealand; SEA - Southeast Asia; ENA - Europe and 546 North Asia; NAM - North and Central America; SAM - South America.

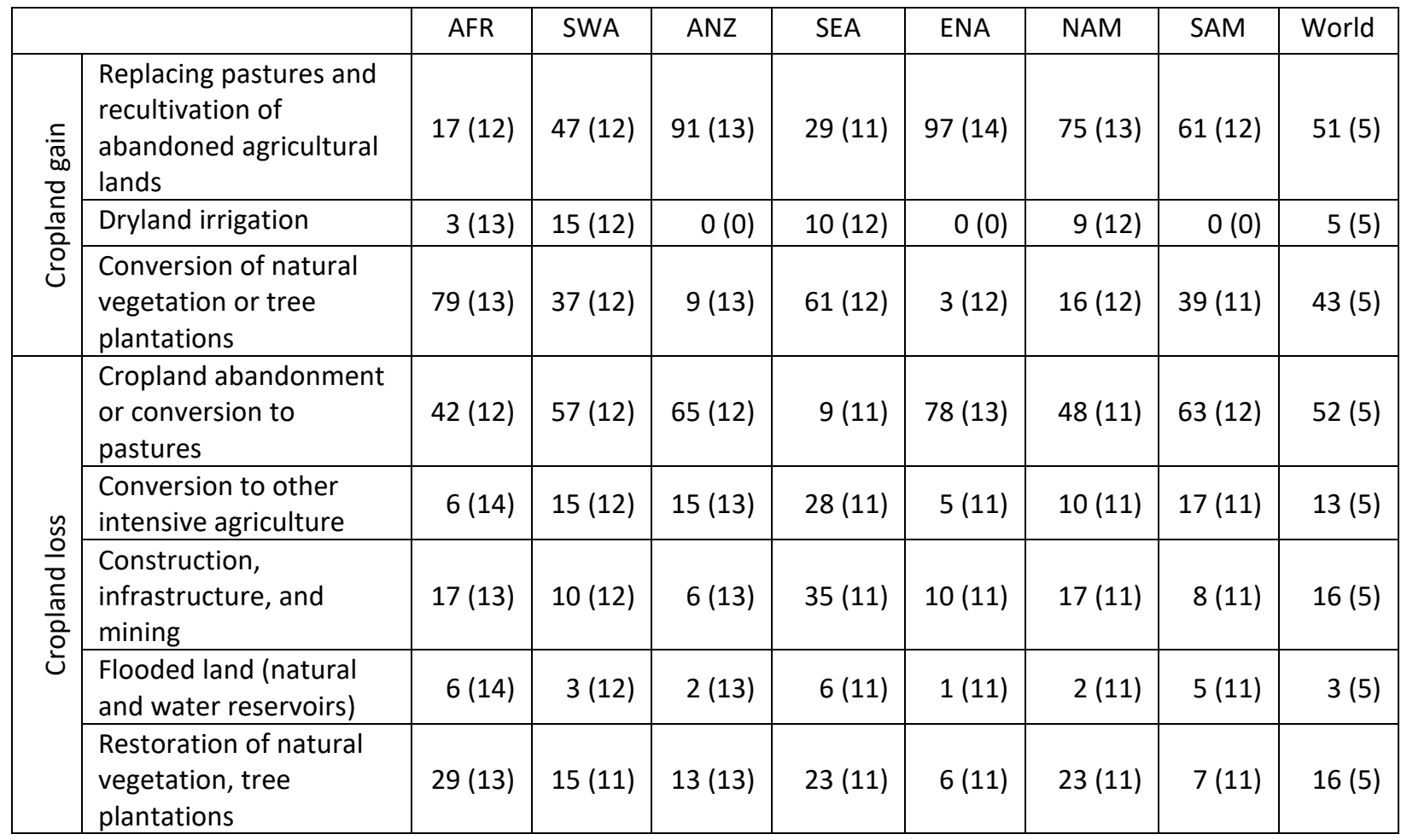


550 Extended Data Table 3. Regional and global map accuracy metrics (expressed as percentage).

551 OA stands for overall accuracy, UA for user's accuracy, and PA for producer's accuracy.

552 Standard errors of accuracy metrics are shown in parenthesis.

\begin{tabular}{|c|c|c|c|c|c|c|}
\hline & & \begin{tabular}{|l|} 
Cropland \\
2000-2003
\end{tabular} & $\begin{array}{l}\text { Cropland } \\
2016-2019\end{array}$ & $\begin{array}{l}\text { Stable } \\
\text { cropland }\end{array}$ & $\begin{array}{l}\text { Cropland } \\
\text { gain }\end{array}$ & $\begin{array}{l}\text { Cropland } \\
\text { loss }\end{array}$ \\
\hline \multirow{3}{*}{ Africa } & $O A$ & $96.9(0.7)$ & $96.5(0.8)$ & $97.2(0.6)$ & $97.9(0.6)$ & $99.4(0.3)$ \\
\hline & $U A$ & $71.3(4.1)$ & $77.3(3.2)$ & $71.9(4.6)$ & $57(5)$ & $48(5)$ \\
\hline & $P A$ & $65.8(8.3)$ & $70.6(7.9)$ & $64.6(8.2)$ & $49.4(12)$ & $39.9(21.5)$ \\
\hline \multirow{3}{*}{ Southwest Asia } & $O A$ & $96.2(0.7)$ & $96.2(0.7)$ & $95.7(0.8)$ & $98.6(0.2)$ & $98.9(0.3)$ \\
\hline & $U A$ & $90.1(2.7)$ & $87.5(2.8)$ & $86(3.5)$ & $59(4.9)$ & $66(4.8)$ \\
\hline & $P A$ & $85(3.2)$ & $89.2(3.2)$ & $82.5(3.5)$ & $85.9(8.6)$ & $52.1(10.7)$ \\
\hline \multirow{3}{*}{$\begin{array}{l}\text { Australia and New } \\
\text { Zealand }\end{array}$} & $O A$ & $99.1(0.2)$ & $98.9(0.2)$ & $99.2(0.2)$ & $99.6(0.1)$ & $99.9(0)$ \\
\hline & $U A$ & $86(3.2)$ & $84.6(3)$ & $88.5(3.3)$ & $57(5)$ & $54(5)$ \\
\hline & $P A$ & $98.7(0.4)$ & $96.8(2.5)$ & $95.8(1.6)$ & $73.8(19.1)$ & $100(0)$ \\
\hline \multirow{3}{*}{ Southeast Asia } & $O A$ & $97.3(0.6)$ & $96.6(0.7)$ & $96.7(0.7)$ & $99.3(0.1)$ & $99.2(0.2)$ \\
\hline & $U A$ & $92.8(2.3)$ & $86.5(2.8)$ & $87(3.4)$ & $69(4.6)$ & $78(4.2)$ \\
\hline & $P A$ & $83.8(4.2)$ & $84.1(4.2)$ & $80.1(4.6)$ & $92.4(6.3)$ & $60.6(9.3)$ \\
\hline \multirow{3}{*}{$\begin{array}{l}\text { Europe and North } \\
\text { Asia }\end{array}$} & $O A$ & $96.8(0.7)$ & $96.8(0.7)$ & $96.1(0.7)$ & $99.2(0.2)$ & $99.6(0.1)$ \\
\hline & $U A$ & $93.1(2.2)$ & $93.6(2)$ & $92.7(2.7)$ & $71(4.6)$ & $79(4.1)$ \\
\hline & $P A$ & $86.4(3.3)$ & $86.1(3.3)$ & $79.3(3.9)$ & $83.1(9.3)$ & $98.8(1.2)$ \\
\hline \multirow{3}{*}{$\begin{array}{l}\text { North and Central } \\
\text { America }\end{array}$} & $O A$ & $98.5(0.5)$ & $97.8(0.5)$ & $98.6(0.4)$ & $99(0.3)$ & $99.4(0.3)$ \\
\hline & $U A$ & $93.6(2.2)$ & $90.8(2.3)$ & $93(2.6)$ & $67(4.7)$ & $82(3.9)$ \\
\hline & $P A$ & $96.2(2.2)$ & $94.7(2.6)$ & $97(1.7)$ & 69.7 (14.9) & $72.2(14.1)$ \\
\hline \multirow{3}{*}{ South America } & $O A$ & $99.5(0.2)$ & $99.1(0.3)$ & $99.4(0.2)$ & $99.3(0.3)$ & $99.8(0)$ \\
\hline & $U A$ & $94.1(2)$ & $94.5(1.6)$ & $93.9(2.4)$ & $88(3.3)$ & $76(4.3)$ \\
\hline & $P A$ & $94.3(3.5)$ & $92(3.9)$ & $90.7(4)$ & $83.7(7.9)$ & $89.2(9.6)$ \\
\hline \multirow{3}{*}{ World } & $O A$ & $97.5(0.2)$ & $97.2(0.3)$ & $97.3(0.2)$ & $98.9(0.1)$ & $99.4(0.1)$ \\
\hline & $U A$ & $90(1.1)$ & $88.5(1)$ & $88.3(1.3)$ & $67.4(1.9)$ & $73.3(1.9)$ \\
\hline & $P A$ & $86(1.8)$ & 86.4 (1.9) & $82.9(1.9)$ & $73.3(5.8)$ & $70.3(6.4)$ \\
\hline
\end{tabular}


556 Extended Data Table 4. Map-based annual cropland area change (Mha year ${ }^{-1}$ ).

\begin{tabular}{|l|c|c|c|c|}
\hline & $2004-2007$ & $2008-2011$ & $2012-2015$ & $2016-2019$ \\
\hline Africa & 1.7 & 2.4 & 3.7 & 3.9 \\
\hline Southwest Asia & 1.8 & 1.2 & 1.8 & 1.7 \\
\hline Australia and New Zealand & 0.3 & 0.1 & 0.3 & 0.2 \\
\hline Southeast Asia & 0.4 & 0.5 & 1.1 & 1.0 \\
\hline Europe and North Asia & -1.2 & 0.1 & 0.7 & 0.2 \\
\hline North and Central America & -0.5 & 0.1 & 1.0 & 0.6 \\
\hline South America & 2.7 & 2.0 & 2.3 & 1.5 \\
\hline World & 5.1 & 6.3 & 10.9 & 9.0 \\
\hline
\end{tabular}

557

558 
560 Extended Data Table 5. Average annual net primary production (NPP) within cropland area, Pg $561 \mathrm{C} \mathrm{yr}^{-1}$. The average value is provided for each four-year interval within the corresponding 562 cropland map. The year 2000 was excluded due to incomplete MODIS data, and the three-year 563 average for 2001-2003 was provided instead. Standard deviations of annual values are shown in 564 parenthesis ( $\left.\mathrm{Pg} \mathrm{C} \mathrm{yr}^{-1}\right)$.

\begin{tabular}{|l|l|l|l|l|l|}
\hline & $2001-2003$ & $2004-2007$ & $2008-2011$ & $2012-2015$ & $2016-2019$ \\
\hline Africa & $0.58(0.02)$ & $0.63(0.01)$ & $0.7(0.02)$ & $0.79(0.02)$ & $0.88(0.03)$ \\
\hline Southwest Asia & $0.55(0.03)$ & $0.61(0.02)$ & $0.63(0.05)$ & $0.62(0.05)$ & $0.65(0.03)$ \\
\hline $\begin{array}{l}\text { Australia and New } \\
\text { Zealand }\end{array}$ & $0.2(0.02)$ & $0.2(0.02)$ & $0.22(0.02)$ & $0.22(0.01)$ & $0.22(0.03)$ \\
\hline Southeast Asia & $0.74(0.04)$ & $0.76(0.01)$ & $0.78(0.02)$ & $0.83(0.02)$ & $0.86(0.03)$ \\
\hline $\begin{array}{l}\text { Europe and North } \\
\text { Asia }\end{array}$ & $1.08(0.02)$ & $1.11(0.03)$ & $1.09(0.05)$ & $1.1(0.05)$ & $1.14(0.01)$ \\
\hline $\begin{array}{l}\text { North and Central } \\
\text { America }\end{array}$ & $0.83(0.05)$ & $0.91(0.05)$ & $0.92(0.05)$ & $0.92(0.05)$ & $0.97(0.06)$ \\
\hline South America & $0.44(0.03)$ & $0.57(0.01)$ & $0.64(0.04)$ & $0.74(0.02)$ & $0.82(0.02)$ \\
\hline World & $4.43(0.15)$ & $4.8(0.08)$ & $4.98(0.07)$ & $5.21(0.14)$ & $5.53(0.01)$ \\
\hline
\end{tabular}


568 Supplementary Information

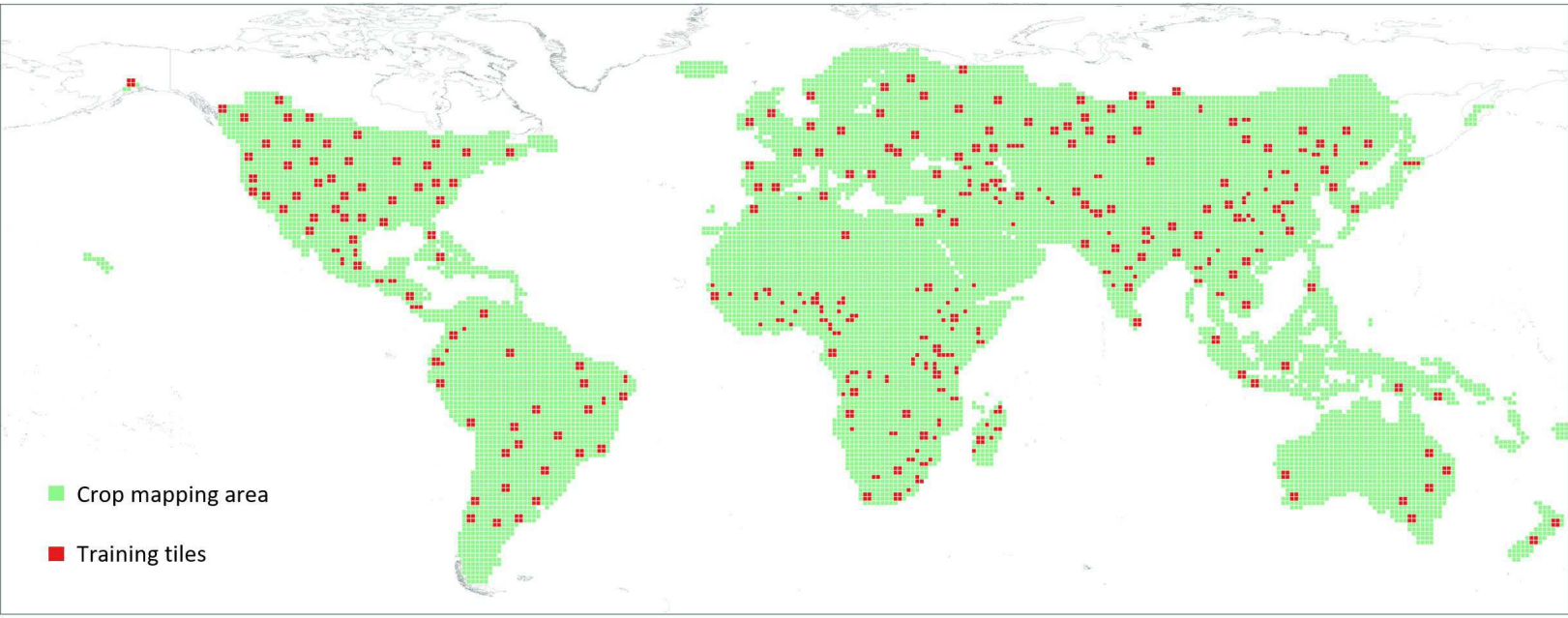

570 Supplementary Information Fig. 1. Cropland mapping extent (a set of processed $1^{\circ} \times 1^{\circ}$ Landsat 571 ARD tiles) and training tiles (which were separately classified to create a global training set). 


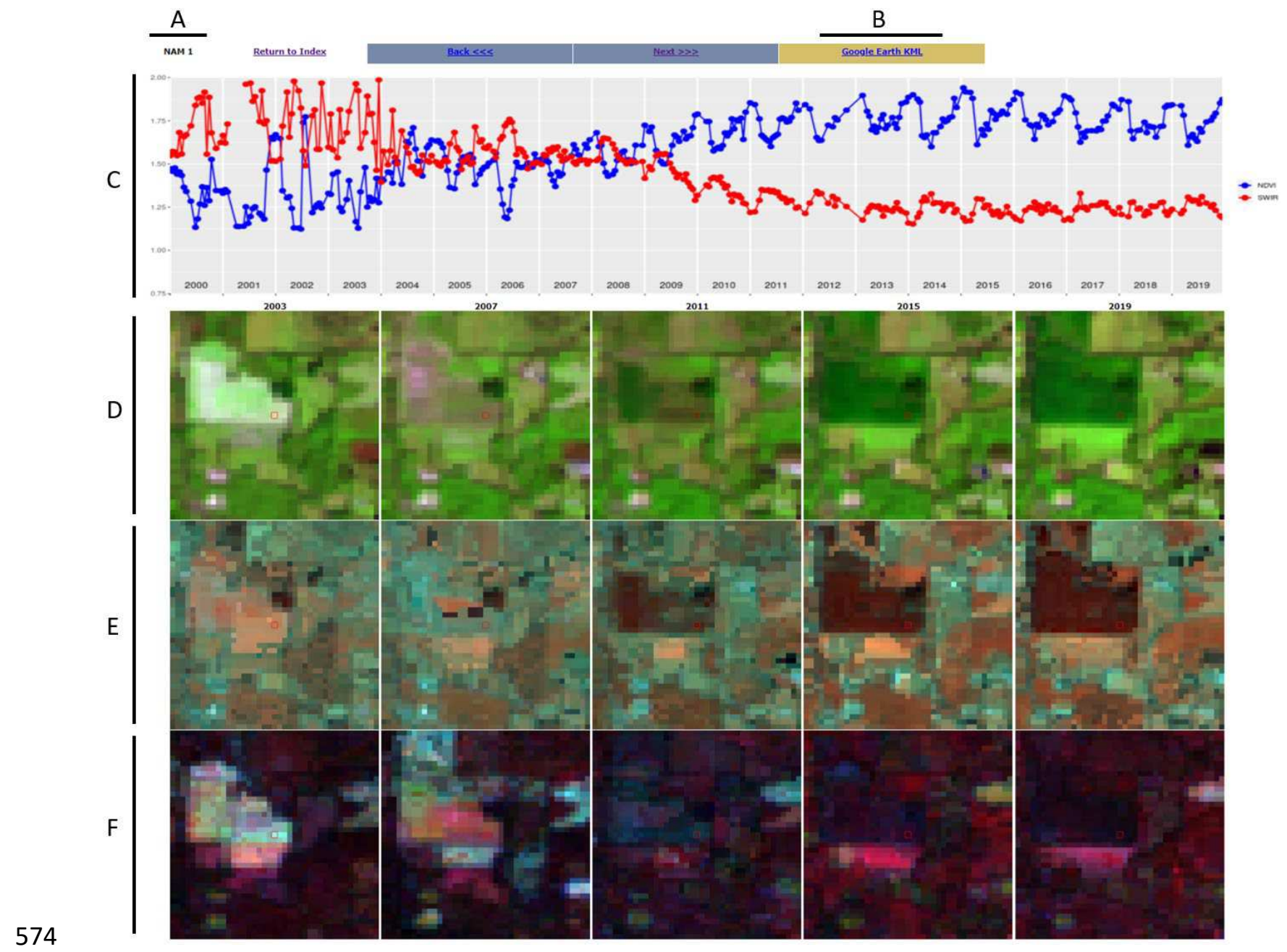

575 Supplementary Information Fig. 2. Online image interpretation interface. A - sample ID. B 576 link to Google Earth interface (provides sample outline). C - Landsat ARD 16-day clear-sky 577 NDVI and shortwave infrared band $(1.6 \mu \mathrm{m})$ normalized surface reflectance for the sample pixel. 578 NDVI value ( -1 to 1$)$ scaled to the range $0-2$, and reflectance (0 to 1$)$ scaled to range $1-3$. D 579 Landsat interquartile means for each time interval (2000-2003, 2004-2007, 2008-2011, 2012580 2015, 2016-2019) using band combination SWIR $(1.6 \mu \mathrm{m}) / \mathrm{NIR} / \mathrm{Red}$. E - Landsat maximum 581 NDVI composite for each time interval using band combination NIR / SWIR (1.6 $\mu \mathrm{m}) / \mathrm{SWIR}$ $582(2.2 \mu \mathrm{m}) . \mathrm{F}$ - Landsat snow-free season amplitude using band combination NIR / SWIR (2.2 $583 \mu \mathrm{m}) /$ NDVI. In each Landsat composite the selected sample pixel is outlined in red. 
587 Supplementary Information Table 1. Landsat multi-temporal metrics. Q1 and Q3 stand for $1^{\text {st }}$ 588 and $3^{\text {rd }}$ quartiles; NDVI stands for the Normalized Difference Vegetation Index.

Metrics for individual spectral bands and indices

\begin{tabular}{l|l}
\hline Annual 16-day observation data & $\begin{array}{l}\text { Statistics extracted for each band (index) and recoded as } \\
\text { metrics }\end{array}$ \\
\hline Normalized surface reflectance: & $\begin{array}{l}\text { Minimum; Maximum; Median; Average; Average between } \\
\text { min and Q1; Average between Q3 and max; Average } \\
\text { Blue }(482 \mathrm{~nm}) ; \text { Green }(561 \mathrm{~nm}) ; \text { Red }(654 \mathrm{~nm}) ; \\
\text { NIR }(864 \mathrm{~nm}) ; \text { SWIR1 }(1609 \mathrm{~nm}) ; \text { SWIR2 }(2201 \mathrm{~nm}) .\end{array}$ \\
$\begin{array}{l}\text { Normalized ratios: } \\
\text { NIR/Green; NIR/Red; NIR/SWIR1; NIR/SWIR2; SWIR1/SWIR2. } \\
\text { Other indices: }\end{array}$ & $\begin{array}{l}\text { interval values); Amplitude min to max; Amplitude Q1 to Q3; } \\
\text { Amplitude median to max. }\end{array}$ \\
\hline Spectral variability index; Tasseled Cap Greenness. & \\
\hline
\end{tabular}

Metrics derived from 16-day observations ordered by a corresponding variable

\begin{tabular}{|c|c|c|}
\hline Variable used for observation ordering & Annual 16-day observation data & $\begin{array}{l}\text { Statistics extracted for each band } \\
\text { (index) and recoded as metrics }\end{array}$ \\
\hline $\begin{array}{l}\text { NIR/Red normalized ratio; NIR/SWIR2 } \\
\text { normalized ratio; brightness } \\
\text { temperature. }\end{array}$ & $\begin{array}{l}\text { Normalized surface reflectance: } \\
\text { Blue (482 nm); Green (561 nm); Red } \\
(654 \mathrm{~nm}) ; \text { NIR (864 nm); SWIR1 (1609 } \\
\text { nm); SWIR2 (2201 nm). }\end{array}$ & $\begin{array}{l}\text { Minimum; Maximum; Average } \\
\text { between min and Q1; Average } \\
\text { between Q3 and max; Amplitude min } \\
\text { to max; Amplitude Q1 to Q3. }\end{array}$ \\
\hline
\end{tabular}


594 Supplementary Information Table 2. Strata definitions. For all strata, only land pixels were 595 considered; pixels labeled as permanent water and snow/ice in the Landsat ARD data quality 596 layer were excluded.

\begin{tabular}{|l|l|}
\hline Stratum ID & Stratum definition \\
\hline 1 & Cropland detected for both 2000-2003 and 2016-2019 intervals (stable cropland) \\
\hline 2 & Cropland detected for 2016-2019 but not for 2000-2003 (cropland gain) \\
\hline 3 & Cropland detected for 2000-2003 but not for 2016-2019 (cropland loss) \\
\hline 4 & $\begin{array}{l}\text { Possible cropland omission. Includes pixels that were not mapped as cropland and either (a) } \\
\text { were identified as crops by the USGS cropland map or (b) had decision tree-based cropland } \\
\text { likelihood between 0.1 and 0.5. for either time interval. }\end{array}$ \\
\hline 5 & No cropland detected. \\
\hline
\end{tabular}


599 Supplementary Information Table 3. Regional strata design for sample analysis. From each 600 stratum, we randomly sampled 100 Landsat data pixels. Region abbreviations (in square 601 brackets) used in sample interpretation interface

602 https://glad.geog.umd.edu/Potapov/Global_Crop/region_index.html.

\begin{tabular}{|c|c|c|c|}
\hline Region & Stratum ID & Stratum area, Mha & N Landsat data pixels \\
\hline \multirow[t]{5}{*}{ Africa [AFR] } & 1 & 127.526 & 1734945656 \\
\hline & 2 & 62.108 & 832287249 \\
\hline & 3 & 15.089 & 205379304 \\
\hline & 4 & 980.335 & 13144624830 \\
\hline & 5 & 1778.860 & 24678278719 \\
\hline \multirow[t]{5}{*}{ Southwest Asia [SWA] } & 1 & 208.332 & 3178440471 \\
\hline & 2 & 42.586 & 658784671 \\
\hline & 3 & 16.555 & 272983747 \\
\hline & 4 & 327.859 & 5282381360 \\
\hline & 5 & 904.372 & 14276931819 \\
\hline \multirow{5}{*}{$\begin{array}{l}\text { Australia and New } \\
\text { Zealand [ANZ] }\end{array}$} & 1 & 40.840 & 632262477 \\
\hline & 2 & 5.178 & 80371180 \\
\hline & 3 & 1.992 & 30780348 \\
\hline & 4 & 106.495 & 1595940550 \\
\hline & 5 & 639.163 & 9224591599 \\
\hline \multirow[t]{5}{*}{ Southeast Asia [SEA] } & 1 & 153.584 & 2417025020 \\
\hline & 2 & 30.896 & 480905111 \\
\hline & 3 & 19.331 & 295816615 \\
\hline & 4 & 360.637 & 5428379429 \\
\hline & 5 & 1066.219 & 16822192585 \\
\hline \multirow{5}{*}{$\begin{array}{l}\text { Europe and North Asia } \\
\text { [ENA] }\end{array}$} & 1 & 204.192 & 4100803095 \\
\hline & 2 & 29.461 & 610382468 \\
\hline & 3 & 30.546 & 641970865 \\
\hline & 4 & 328.740 & 6788487596 \\
\hline & 5 & 837.569 & 19714599814 \\
\hline \multirow{5}{*}{$\begin{array}{l}\text { North and Central } \\
\text { America [NAM] }\end{array}$} & 1 & 180.202 & 3166064873 \\
\hline & 2 & 21.335 & 367406884 \\
\hline & 3 & 16.702 & 280651515 \\
\hline & 4 & 326.299 & 5342386489 \\
\hline & 5 & 783.962 & 13579648743 \\
\hline \multirow[t]{5}{*}{ South America [SAM] } & 1 & 67.955 & 1006589638 \\
\hline & 2 & 41.307 & 585378867 \\
\hline & 3 & 7.472 & 109594042 \\
\hline & 4 & 288.612 & 4019591418 \\
\hline & 5 & 1325.860 & 18253454476 \\
\hline
\end{tabular}

603 
604 Supplementary Information Table 4. National cropland area (map-based estimates), ha $\times 10^{3}$.

\begin{tabular}{|c|c|c|c|c|c|}
\hline & $2000-2003$ & $2004-2007$ & $2008-2011$ & $2012-2015$ & 2016-2019 \\
\hline Afghanistan & 2084.9 & 2426.6 & 2704.1 & 2907.7 & 3165.7 \\
\hline Albania & 300.3 & 270.0 & 260.7 & 255.0 & 243.5 \\
\hline Algeria & 4999.4 & 5382.4 & 5578.9 & 5579.3 & 5635.6 \\
\hline Andorra & 0.1 & 0.1 & 0.1 & 0.1 & 0.1 \\
\hline Angola & 1131.6 & 1213.3 & 1424.3 & 2142.3 & 2994.9 \\
\hline Antigua and Barbuda & 0.2 & 0.1 & 0.1 & 0.2 & 1.3 \\
\hline Argentina & 37695.1 & 41071.4 & 43333.9 & 44310.8 & 43358.3 \\
\hline Armenia & 301.8 & 282.9 & 289.2 & 326.4 & 365.5 \\
\hline Australia & 42368.0 & 43412.6 & 43602.7 & 44706.0 & 45469.6 \\
\hline Austria & 1303.6 & 1313.3 & 1318.7 & 1312.4 & 1264.8 \\
\hline Azerbaijan & 1727.0 & 1652.9 & 1727.1 & 1928.6 & 2124.5 \\
\hline Bahamas & 1.3 & 1.2 & 1.2 & 1.1 & 1.2 \\
\hline Bahrain & 0.3 & 0.2 & 0.2 & 0.2 & 0.3 \\
\hline Bangladesh & 6592.0 & 6638.9 & 6631.5 & 6669.5 & 6556.9 \\
\hline Barbados & 3.9 & 3.2 & 3.3 & 5.7 & 8.0 \\
\hline Belarus & 5150.2 & 5410.2 & 5677.1 & 5904.1 & 5673.7 \\
\hline Belgium & 878.7 & 888.0 & 898.4 & 916.3 & 933.2 \\
\hline Belize & 21.4 & 17.3 & 20.7 & 34.6 & 56.0 \\
\hline Benin & 1851.1 & 1915.0 & 2101.5 & 2381.9 & 2698.1 \\
\hline Bhutan & 9.9 & 9.9 & 10.7 & 11.1 & 12.6 \\
\hline Bolivia & 1370.7 & 1630.6 & 1965.3 & 2305.4 & 2709.9 \\
\hline Bosnia and Herzegovina & 200.3 & 202.7 & 221.0 & 235.1 & 237.9 \\
\hline Botswana & 115.8 & 119.0 & 151.4 & 214.4 & 284.9 \\
\hline Brazil & 30101.7 & 36350.9 & 40625.0 & 47535.0 & 53203.4 \\
\hline Brunei & 0.0 & 0.0 & 0.0 & 0.2 & 0.3 \\
\hline Bulgaria & 3443.5 & 3409.3 & 3507.4 & 3669.8 & 3706.5 \\
\hline Burkina Faso & 2646.3 & 2967.1 & 3322.5 & 3709.7 & 4242.1 \\
\hline Burundi & 285.5 & 293.5 & 315.7 & 349.6 & 409.2 \\
\hline Cambodia & 4383.9 & 4644.6 & 4902.3 & 5518.7 & 5966.8 \\
\hline Cameroon & 1254.4 & 1343.6 & 1456.3 & 1798.6 & 2090.7 \\
\hline Canada & 36998.6 & 37005.2 & 36988.6 & 37613.1 & 38216.2 \\
\hline Cayman Islands & 0.0 & 0.0 & 0.1 & 0.1 & 0.1 \\
\hline Central African Republic & 63.9 & 56.2 & 76.7 & 147.6 & 256.0 \\
\hline Chad & 3330.2 & 3774.2 & 4246.5 & 5090.9 & 5934.5 \\
\hline Chile & 1070.6 & 1016.2 & 1063.7 & 1146.9 & 1202.1 \\
\hline China & 117968.0 & 118426.7 & 119422.4 & 121364.1 & 123346.5 \\
\hline Colombia & 545.0 & 501.0 & 542.5 & 654.4 & 902.2 \\
\hline Costa Rica & 89.1 & 91.7 & 112.8 & 140.9 & 174.9 \\
\hline Cote d'Ivoire & 691.3 & 680.0 & 800.4 & 1020.1 & 1361.2 \\
\hline
\end{tabular}




\begin{tabular}{|c|c|c|c|c|c|}
\hline Croatia & 923.3 & 908.2 & 918.2 & 922.7 & 916.2 \\
\hline Cuba & 1805.1 & 1494.6 & 1377.8 & 1328.8 & 1306.8 \\
\hline Cyprus & 270.5 & 253.9 & 250.9 & 262.0 & 271.0 \\
\hline Czech Republic & 2855.0 & 2800.3 & 2742.4 & 2712.4 & 2667.1 \\
\hline $\begin{array}{l}\text { Democratic Republic of the } \\
\text { Congo }\end{array}$ & 1535.4 & 1600.7 & 1899.3 & 2650.6 & 3811.0 \\
\hline Denmark & 2221.4 & 2242.6 & 2262.7 & 2275.3 & 2246.4 \\
\hline Dominican Republic & 293.2 & 291.3 & 311.7 & 331.8 & 380.1 \\
\hline East Timor & 45.8 & 46.5 & 49.0 & 50.9 & 54.3 \\
\hline Ecuador & 293.4 & 285.6 & 309.8 & 346.4 & 397.8 \\
\hline Egypt & 2913.4 & 3000.9 & 3100.4 & 3255.7 & 3451.3 \\
\hline El Salvador & 72.3 & 65.7 & 67.1 & 74.1 & 78.2 \\
\hline Eritrea & 266.0 & 261.6 & 270.7 & 276.8 & 287.1 \\
\hline Estonia & 420.1 & 561.7 & 616.3 & 660.1 & 669.7 \\
\hline Ethiopia & 14178.0 & 14091.4 & 14607.0 & 15444.9 & 16060.8 \\
\hline Fiji & 28.6 & 29.3 & 32.1 & 35.2 & 38.2 \\
\hline Finland & 1869.0 & 1926.8 & 1944.4 & 1968.8 & 1967.9 \\
\hline France & 16827.0 & 17042.7 & 17153.8 & 17271.9 & 17482.2 \\
\hline French Guiana & 5.1 & 4.8 & 3.5 & 1.9 & 1.1 \\
\hline Gabon & 1.4 & 1.1 & 1.7 & 3.4 & 3.8 \\
\hline Gambia & 247.5 & 252.2 & 257.9 & 271.1 & 282.5 \\
\hline Georgia & 407.9 & 359.3 & 349.4 & 360.5 & 347.6 \\
\hline Germany & 12023.5 & 12095.7 & 12289.9 & 12386.0 & 12289.4 \\
\hline Ghana & 1948.9 & 2122.1 & 2304.6 & 2594.6 & 2995.1 \\
\hline Greece & 2321.1 & 2202.7 & 2166.1 & 2110.7 & 2046.2 \\
\hline Guadeloupe & 10.7 & 9.2 & 9.9 & 12.5 & 14.3 \\
\hline Guatemala & 287.7 & 303.6 & 329.9 & 362.3 & 350.2 \\
\hline Guernsey & 0.5 & 0.4 & 0.4 & 0.4 & 0.3 \\
\hline Guinea & 147.8 & 153.1 & 176.4 & 241.7 & 333.1 \\
\hline Guinea-Bissau & 34.1 & 36.0 & 39.7 & 46.4 & 60.1 \\
\hline Guyana & 120.5 & 116.9 & 124.5 & 143.4 & 141.7 \\
\hline Haiti & 72.9 & 65.6 & 70.5 & 77.0 & 86.8 \\
\hline Honduras & 93.0 & 75.2 & 82.8 & 97.0 & 114.7 \\
\hline Hong Kong & 0.1 & 0.0 & 0.0 & 0.0 & 0.1 \\
\hline Hungary & 4681.5 & 4649.5 & 4634.1 & 4638.1 & 4568.7 \\
\hline Iceland & 46.7 & 37.1 & 42.1 & 46.9 & 54.3 \\
\hline India & 121370.8 & 126890.6 & 130182.1 & 134066.0 & 136899.1 \\
\hline Indonesia & 6903.7 & 7146.4 & 7357.9 & 8020.5 & 8770.6 \\
\hline Iran & 12179.4 & 13087.3 & 13254.3 & 13464.8 & 14081.8 \\
\hline Iraq & 4713.3 & 4090.2 & 4051.7 & 5073.9 & 6296.5 \\
\hline Ireland & 447.7 & 398.9 & 398.3 & 429.3 & 469.8 \\
\hline Isle of Man & 7.8 & 7.1 & 7.3 & 6.9 & 7.5 \\
\hline
\end{tabular}




\begin{tabular}{|c|c|c|c|c|c|}
\hline Israel & 438.6 & 425.8 & 425.0 & 430.1 & 426.4 \\
\hline Italy & 7817.8 & 7693.5 & 7603.4 & 7617.4 & 7547.1 \\
\hline Jamaica & 30.2 & 34.4 & 35.0 & 33.4 & 27.7 \\
\hline Japan & 3100.6 & 3146.7 & 3154.1 & 3172.3 & 3187.0 \\
\hline Jersey & 4.3 & 4.1 & 4.1 & 4.1 & 4.2 \\
\hline Jordan & 241.2 & 231.9 & 231.9 & 244.2 & 259.1 \\
\hline Kazakhstan & 20738.7 & 20745.9 & 21097.4 & 21644.2 & 22031.2 \\
\hline Kenya & 4238.2 & 4497.3 & 4981.4 & 5433.1 & 5788.1 \\
\hline Kosovo & 200.2 & 205.3 & 209.5 & 210.2 & 184.3 \\
\hline Kuwait & 4.6 & 4.7 & 5.1 & 7.1 & 9.9 \\
\hline Kyrgyzstan & 1173.3 & 1300.7 & 1361.2 & 1393.7 & 1419.3 \\
\hline Laos & 966.3 & 1028.1 & 1111.8 & 1246.3 & 1360.5 \\
\hline Latvia & 562.2 & 702.8 & 789.1 & 927.6 & 1017.2 \\
\hline Lebanon & 108.7 & 101.8 & 102.9 & 104.8 & 109.1 \\
\hline Lesotho & 211.6 & 210.4 & 213.9 & 228.2 & 246.2 \\
\hline Liberia & 0.1 & 0.2 & 0.3 & 0.4 & 0.8 \\
\hline Libya & 734.8 & 744.7 & 792.0 & 846.7 & 914.6 \\
\hline Liechtenstein & 0.8 & 0.8 & 0.8 & 0.8 & 0.8 \\
\hline Lithuania & 1182.7 & 1429.8 & 1586.5 & 1830.0 & 1966.0 \\
\hline Luxembourg & 53.2 & 52.1 & 52.3 & 52.8 & 53.1 \\
\hline Macedonia & 329.0 & 313.5 & 310.3 & 305.4 & 293.2 \\
\hline Madagascar & 1252.5 & 1370.0 & 1463.5 & 1697.7 & 1972.3 \\
\hline Malawi & 1721.9 & 1823.3 & 1937.6 & 2137.8 & 2319.7 \\
\hline Malaysia & 306.3 & 301.1 & 296.9 & 298.8 & 307.4 \\
\hline Mali & 4468.4 & 4871.3 & 5258.6 & 5675.9 & 6135.5 \\
\hline Malta & 3.3 & 3.0 & 3.2 & 3.5 & 4.0 \\
\hline Martinique & 0.8 & 1.2 & 1.5 & 2.3 & 3.4 \\
\hline Mauritania & 23.0 & 17.7 & 22.8 & 35.9 & 50.9 \\
\hline Mexico & 10035.8 & 10110.3 & 10500.1 & 10951.3 & 11168.6 \\
\hline Moldova & 1873.0 & 1844.9 & 1832.1 & 1841.0 & 1853.7 \\
\hline Mongolia & 380.9 & 374.3 & 409.5 & 455.5 & 561.1 \\
\hline Montenegro & 16.5 & 15.8 & 15.5 & 14.3 & 12.5 \\
\hline Morocco & 6259.4 & 6328.7 & 6435.5 & 6369.2 & 6311.3 \\
\hline Mozambique & 1789.8 & 1970.3 & 2359.2 & 3069.3 & 3940.2 \\
\hline Myanmar & 10551.8 & 10780.4 & 11009.7 & 11392.9 & 11739.0 \\
\hline Namibia & 360.7 & 388.8 & 421.2 & 512.6 & 582.1 \\
\hline Nepal & 1621.2 & 1671.3 & 1720.9 & 1763.3 & 1827.3 \\
\hline Netherlands & 1016.5 & 996.0 & 987.8 & 985.5 & 982.7 \\
\hline New Caledonia & 1.4 & 1.5 & 1.5 & 1.8 & 2.0 \\
\hline New Zealand & 463.6 & 454.0 & 518.5 & 527.2 & 547.8 \\
\hline Nicaragua & 160.3 & 165.4 & 193.6 & 223.0 & 241.7 \\
\hline
\end{tabular}




\begin{tabular}{|c|c|c|c|c|c|}
\hline Niger & 7090.1 & 7453.4 & 7663.9 & 7817.6 & 8023.8 \\
\hline Nigeria & 28379.6 & 29625.6 & 30780.1 & 32056.3 & 32967.3 \\
\hline North Korea & 1727.2 & 1765.3 & 1804.8 & 1880.4 & 1929.6 \\
\hline Norway & 419.4 & 420.2 & 424.0 & 431.4 & 440.4 \\
\hline Oman & 16.8 & 14.4 & 16.5 & 23.1 & 30.7 \\
\hline Pakistan & 16977.0 & 17831.4 & 18239.4 & 18554.7 & 18906.2 \\
\hline Palestine & 75.4 & 69.3 & 67.8 & 70.0 & 75.3 \\
\hline Panama & 34.6 & 29.2 & 45.4 & 80.0 & 121.3 \\
\hline Papua New Guinea & 15.4 & 14.9 & 15.4 & 17.5 & 23.0 \\
\hline Paraguay & 1518.1 & 1937.8 & 2206.1 & 2529.9 & 2814.7 \\
\hline Peru & 745.8 & 794.5 & 853.0 & 950.8 & 1086.6 \\
\hline Philippines & 3156.9 & 3223.6 & 3286.5 & 3486.4 & 3667.9 \\
\hline Poland & 11619.9 & 11766.3 & 11742.2 & 11869.2 & 11948.8 \\
\hline Portugal & 702.4 & 624.7 & 594.8 & 591.2 & 662.5 \\
\hline Puerto Rico & 25.0 & 17.5 & 18.4 & 19.8 & 27.0 \\
\hline Qatar & 2.8 & 2.9 & 3.8 & 4.9 & 6.7 \\
\hline Republic of Congo & 55.7 & 66.6 & 83.7 & 115.3 & 170.7 \\
\hline Romania & 7231.4 & 6955.7 & 7008.8 & 7418.1 & 7545.1 \\
\hline Russia & 90919.6 & 85969.5 & 85186.5 & 85167.5 & 85260.0 \\
\hline Rwanda & 768.0 & 784.1 & 813.0 & 854.2 & 912.0 \\
\hline Saint Kitts and Nevis & 1.0 & 0.4 & 0.1 & 0.1 & 0.3 \\
\hline Saint Lucia & 0.1 & 0.1 & 0.1 & 0.2 & 0.3 \\
\hline Saint Pierre and Miquelon & 0.2 & 0.2 & 0.2 & 0.2 & 0.2 \\
\hline San Marino & 1.2 & 1.1 & 1.1 & 1.1 & 1.1 \\
\hline Saudi Arabia & 1346.5 & 1284.6 & 1198.4 & 1251.7 & 1298.0 \\
\hline Senegal & 2936.2 & 3077.5 & 3189.6 & 3316.7 & 3410.0 \\
\hline Serbia & 2398.3 & 2426.2 & 2439.4 & 2457.4 & 2445.7 \\
\hline Sierra Leone & 18.1 & 22.1 & 25.2 & 29.0 & 32.2 \\
\hline Singapore & 0.1 & 0.2 & 0.2 & 0.3 & 0.4 \\
\hline Slovakia & 1419.6 & 1380.3 & 1358.0 & 1354.4 & 1342.4 \\
\hline Slovenia & 134.4 & 144.7 & 148.8 & 150.7 & 143.2 \\
\hline Solomon Islands & 0.0 & 0.0 & 0.0 & 0.1 & 0.1 \\
\hline Somalia & 714.6 & 786.8 & 852.1 & 1032.6 & 1179.9 \\
\hline South Africa & 7181.5 & 7040.8 & 6959.3 & 7297.3 & 7731.6 \\
\hline South Korea & 1410.2 & 1349.8 & 1313.2 & 1268.8 & 1249.7 \\
\hline South Sudan & 195.4 & 197.2 & 223.1 & 297.0 & 389.6 \\
\hline Spain & 11586.1 & 11352.1 & 11208.7 & 11344.7 & 11406.3 \\
\hline Sri Lanka & 762.0 & 788.2 & 830.9 & 917.4 & 997.3 \\
\hline Sudan & 14587.1 & 15309.3 & 16081.3 & 17419.9 & 18694.0 \\
\hline Suriname & 37.2 & 33.1 & 35.8 & 39.5 & 40.8 \\
\hline Swaziland & 69.4 & 73.1 & 77.2 & 89.8 & 104.4 \\
\hline
\end{tabular}




\begin{tabular}{|c|c|c|c|c|c|}
\hline Sweden & 1833.9 & 1842.7 & 1849.6 & 1889.0 & 1899.5 \\
\hline Switzerland & 294.7 & 301.6 & 295.3 & 292.5 & 275.0 \\
\hline Syria & 4402.6 & 4247.6 & 4131.2 & 4301.6 & 4560.6 \\
\hline Taiwan & 340.0 & 321.4 & 316.4 & 323.2 & 329.9 \\
\hline Tajikistan & 1054.4 & 1072.7 & 1086.0 & 1093.7 & 1131.6 \\
\hline Tanzania & 9569.9 & 10276.4 & 11621.9 & 13700.2 & 15577.5 \\
\hline Thailand & 16944.4 & 17363.8 & 17386.1 & 17550.8 & 17379.3 \\
\hline Togo & 997.5 & 1018.0 & 1083.5 & 1186.6 & 1338.6 \\
\hline Trinidad and Tobago & 3.4 & 3.7 & 3.9 & 3.6 & 3.3 \\
\hline Tunisia & 1809.0 & 1856.0 & 1871.2 & 1892.9 & 1933.2 \\
\hline Turkey & 17764.7 & 17988.5 & 18091.8 & 18171.3 & 18297.4 \\
\hline Turkmenistan & 2015.6 & 2245.0 & 2366.0 & 2499.1 & 2618.0 \\
\hline Uganda & 3306.1 & 3790.7 & 4309.0 & 5048.2 & 5788.4 \\
\hline Ukraine & 31416.6 & 31236.3 & 31664.8 & 32368.9 & 32705.2 \\
\hline United Arab Emirates & 35.3 & 7.9 & 6.6 & 8.5 & 10.7 \\
\hline United Kingdom & 5739.1 & 5615.4 & 5689.4 & 5849.1 & 5991.7 \\
\hline United States & 146839.8 & 145009.8 & 144912.5 & 147661.2 & 149131.5 \\
\hline Uruguay & 1291.4 & 1695.4 & 2301.5 & 2635.5 & 2673.8 \\
\hline US Virgin Islands & 0.0 & 0.1 & 0.1 & 0.1 & 0.3 \\
\hline Uzbekistan & 5435.8 & 5579.3 & 5612.6 & 5672.0 & 5794.6 \\
\hline Vanuatu & 0.0 & 0.0 & 0.0 & 0.1 & 0.1 \\
\hline Venezuela & 628.3 & 622.6 & 662.2 & 702.7 & 724.7 \\
\hline Vietnam & 5139.5 & 5072.9 & 5019.6 & 5062.7 & 5009.5 \\
\hline Western Sahara & 0.0 & 0.1 & 0.1 & 0.2 & 0.2 \\
\hline Yemen & 532.0 & 474.1 & 501.5 & 563.8 & 628.0 \\
\hline Zambia & 1852.8 & 2077.1 & 2578.9 & 3296.1 & 4082.6 \\
\hline Zimbabwe & 4365.8 & 4520.6 & 4762.8 & 5282.6 & 5823.5 \\
\hline
\end{tabular}

